Document downloaded from:

http://hdl.handle.net/10251/142682

This paper must be cited as:

Buitrago, M.; Sagaseta, J.; Adam, JM. (10-2). Effects of sudden failure of shoring elements in concrete building structures under construction. Engineering Structures. 172:508-522. https://doi.org/10.1016/j.engstruct.2018.06.052

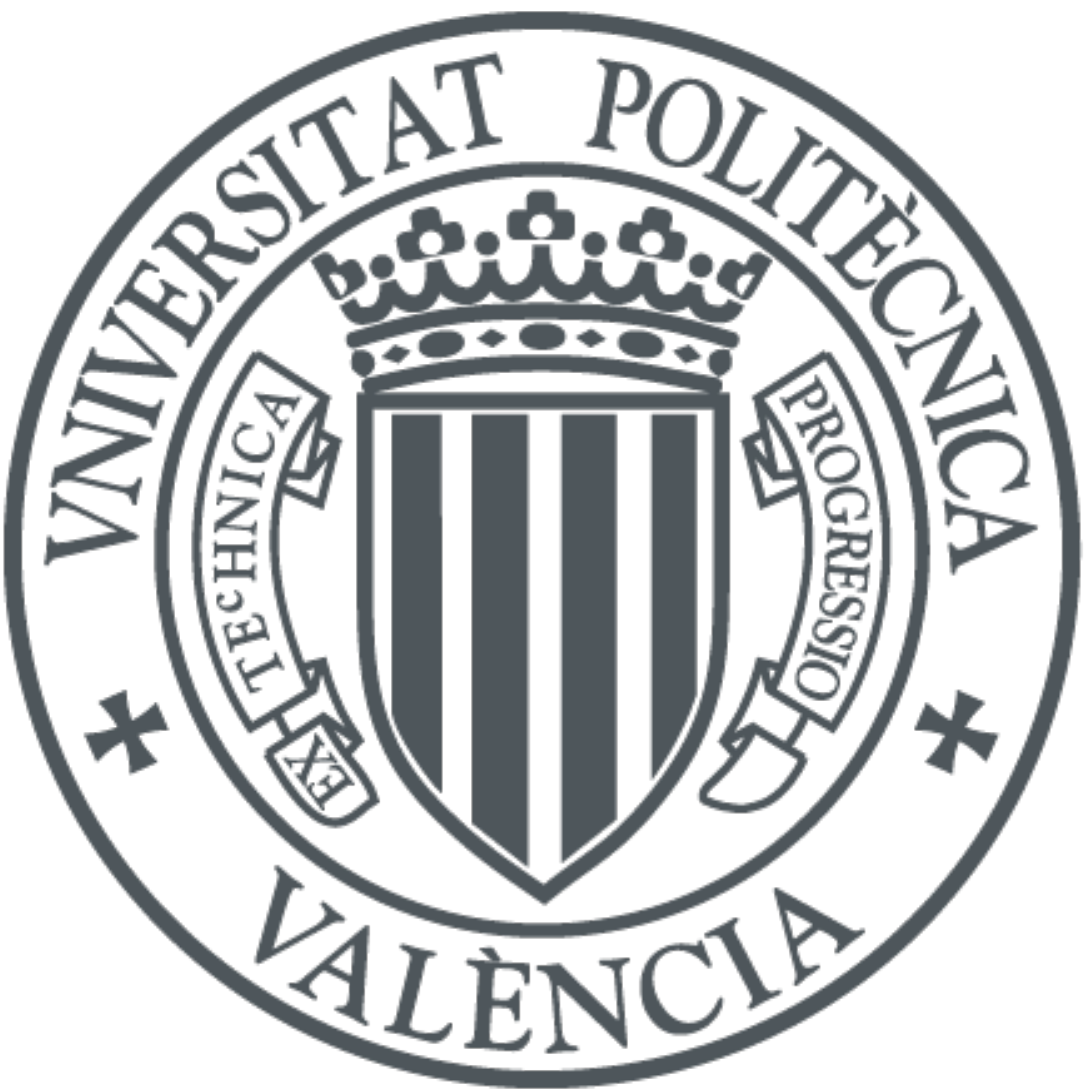

The final publication is available at

https://doi.org/10.1016/j.engstruct.2018.06.052

Copyright Elsevier

Additional Information 


\title{
Effects of sudden failure of shoring elements in concrete building structures under construction
}

\author{
Manuel Buitrago ${ }^{\mathrm{a}}$, Juan Sagaseta ${ }^{\mathrm{b}}$, Jose M. Adam ${ }^{\mathrm{a} *}$ \\ ${ }^{a}$ ICITECH, Universitat Politècnica de València. Camino de Vera s/n, 46022 Valencia, Spain \\ ${ }^{b}$ Department of Civil and Environmental Engineering, University of Surrey, GU2 7XH Guildford, UK \\ *Corresponding author. Tel.: +34 963877000 (Ext. 75621). \\ E-mail addresses: mabuimo1@upv.es (Manuel Buitrago), j.sagaseta@surrey.ac.uk (Juan \\ Sagaseta), joadmar@upv.es (Jose M. Adam*)
}

\section{Abstract}

The most frequently used technique to construct reinforced concrete (RC) building structures is the shoring or propping of successive floors, in which the slabs are supported by the shores until the concrete acquires sufficient strength. A significant number of structural failures have been reported during construction in recent years leading in some cases to the progressive collapse of the whole structure. The collapse often starts with the local failure of a single element which could be due to errors in design or construction and/or due to accidental events. Although this is a well-recognized problem, studies on the effects of local failure in the shoring elements on the integrity of the shoring-structure system have not been carried out in the past. In this work advanced numerical finite element models were carried out of a threestorey RC building and its shoring system. Four scenarios of local failure were considered: sudden removal of a (1) shore, (2) joist and (3) complete shore line; and (4) incorrect selection of shores. The results indicated that the structure-shoring system was able to develop alternative load paths without dynamic amplification effects due to the large stiffness and redundancy of the system without compromising the integrity of the structure but leading to significant damage in the concrete slabs. Design recommendations are also given based on the results from this study, which pretend to be the first study to focus on the structural response 
27 and damage of a building structure under construction after the sudden failure of one or more 28 shores.

29 Keywords: Alternative load path; Buildings; Dynamic amplification factor; Finite element 30 analysis; Progressive collapse; Shore failure. 


\section{Introduction}

Building reinforced concrete (RC) structures involves the use of temporary shoring or propping systems to support the slabs until the concrete is strong enough to support itself. Although there are many types of such systems, the one most commonly used is the shoring of successive floors $[1,2]$, in which the shores distribute the weight of the newly poured slabs among the lower floors. The main components of this system are: shores (s), joists (j) and formwork boards (f) (see Fig. 1). Recovering shores from the lowest level enables the construction of a new upper floor without the need for additional shores. The most basic option of this system consists of the shoring/striking (SS) of individual floors when the slab is able to support its own weight plus the loads transmitted to it from above. Fig. 1 shows the construction phases and these operations in a building with three successively-shored floors.

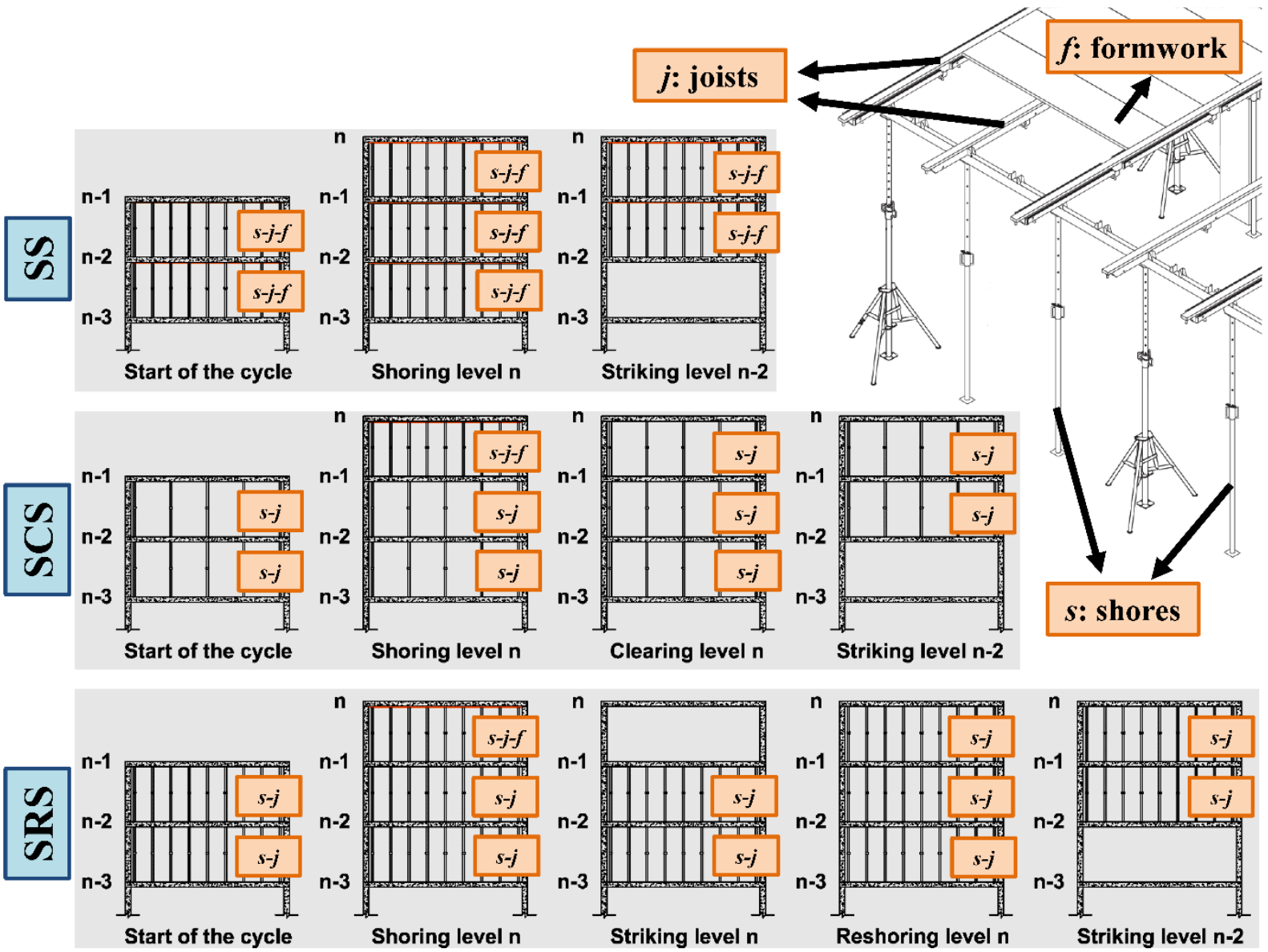

Fig. 1. Shoring system: components and construction processes. 
In order to reduce the costs of this system even further, two other alternatives have been suggested that include an intermediate operation on each floor: clearing or partial striking (C) and re-shoring or back propping (R). The former involves removing more than $50 \%$ of the shoring material some days after the pouring of the slab in order to recover $50 \%$ of the shores (s) and joists (j) and 100\% of the formwork boards (f). Re-shoring consists of removing all the shoring and formwork boards a few days after pouring when the slab is able to bear its own weight (with no or minimal cracking), and then re-install the shores to help support additional future loads. These two construction alternatives are shown in Fig. 1 for three successivelyshored floors (Shoring/Clearing/Striking-SCS, and Shoring/Re-shoring/Striking-SRS).

The design philosophy of temporary structures differs significantly from permanent structures; in the former, the members are highly stressed during short period of time and they can be reused several times. Some of the latest simplified calculation methods that can be used to design these systems include those by Duan and Chen [3], Fang et al [4], Calderón et al [5] and Buitrago et al $[6,7]$. There are commercial pressures to shorten construction cycles to reduce costs which introduce demand on simplicity of the connections and components. Stability has been traditionally identified as one of the main reasons for concern and codes for design (e.g. BS 5975:2008+A1:2011 [8]) generally provide information to ensure sufficient bracing and lateral stability. Design guidelines for temporary works are now starting to introduce clauses to avoid progressive collapse with the idea that local failure of the temporary structures does not lead to failure of the whole structure [8]. This is a shift from traditional views in design practice where local failures in construction works were generally assumed to have negligible consequences compared to permanent works to an extent where collapse due to an accidental event could be acceptable if agreed with the client or relevant authority [9]. (including its probability and consequences) is still not well understood. Due to the temporary 
nature of shoring systems the probability of local failure is higher and the consequences are lower compared to permanent structures. However, it is not well defined to what extent this is critical due to the lack of solid research in this area. According to a recent study by Buitrago et al [10], shore failure is the principal cause of the collapse of buildings under construction and have caused loss of human lives, injuries and material losses. Such failures are mainly due to: loads higher than allowable design loads on the shores, improper shore installation or lack of shore bracing. In addition, other studies on building failures under construction [10-15] have shown that failure can also be due to inadequate design of the structure itself (i.e. insufficient anchorage length of reinforcement bars, insufficient reinforcement for flexure and punching shear or deficient detailing).

The numerical analyses of a RC building structure carried out in this work provide unique and novel evidence on the structural consequences of the structure-shoring system after the local failure of different shoring elements using the concept of notional member removal. This approach is commonly used for robustness analysis of permanent structures in research [1624] and international codes [25-27]. This approach is based on the "sudden" removal of an element (scenario independent approach) to assess the capacity of the structure to redistribute the loads (alternative load path method) and to assess dynamic effects. Advanced dynamic analysis are unlikely to be carried out in design of shoring systems even in category 2 of design checks [8] which includes more complex designs. Therefore, simplified approaches using Dynamic Amplification Factors (DAF) will be needed for design. This work shows that the DAFs used for permanent structures are not directly applicable to structure-shoring systems due to their high redundancy and stiffness compared to traditional permanent structural steel or RC construction. Design recommendations are provided based on the analyses carried out in this work. 
After the Introduction (Section 1), Section 2 describes the building structure considered in

94 the study including loading and construction considerations for the design of the shoring the subject of other studies, can be found in Olmati et al [16]. Fig. 2 shows a 3D view of the system. Section 3 describes the finite element (FE) model used to assess the local failure scenarios and Section 4 presents the results for each scenario. Section 5 contains a discussion of the results together with some recommendations, and the main conclusions drawn from the work are given in Section 6.

\section{Description of the building structure}

The study in this work focused on a three-storey flat-slab RC building in which shoring was used to support the slabs and formwork. This section describes both the building structure and the shoring. The weight of the fresh concrete poured into the top formwork was uniformly distributed among the previously built slabs and the ground by means of the shores as shown in Fig. 2.

\subsection{Building structure}

The building structure considered in this study corresponds to a real office building whose characteristics (geometry, reinforcement, materials) are thoroughly described in CS [28] and which was designed in accordance to Eurocode 2 [25]. The building had three floors with RC flat-slabs $300 \mathrm{~mm}$ thick, $3.5 \mathrm{~m}$ between floors and columns $400 \mathrm{~mm}$ square which were irregularly distributed in plan. A more exhaustive description of the building, which was also building where colours represent the areas with different amount of reinforcement. 


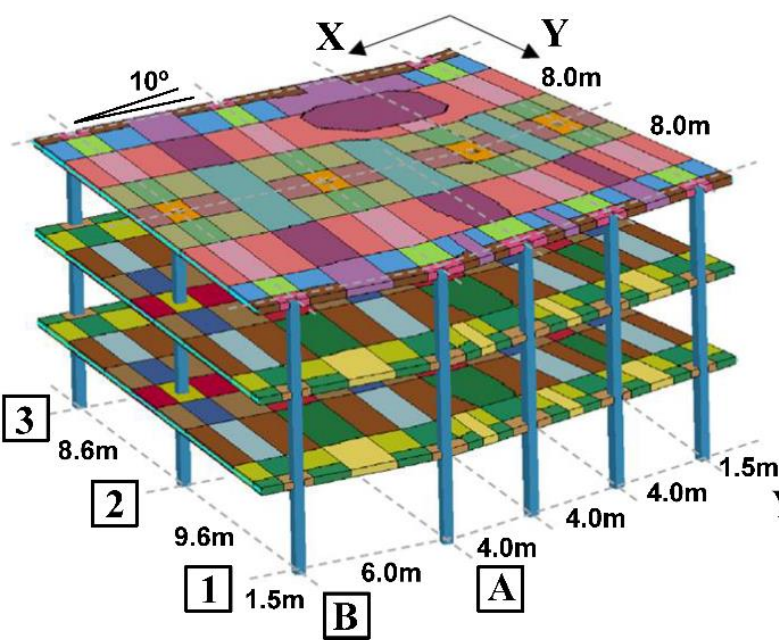

115

116

117

118 loads respectively [32].

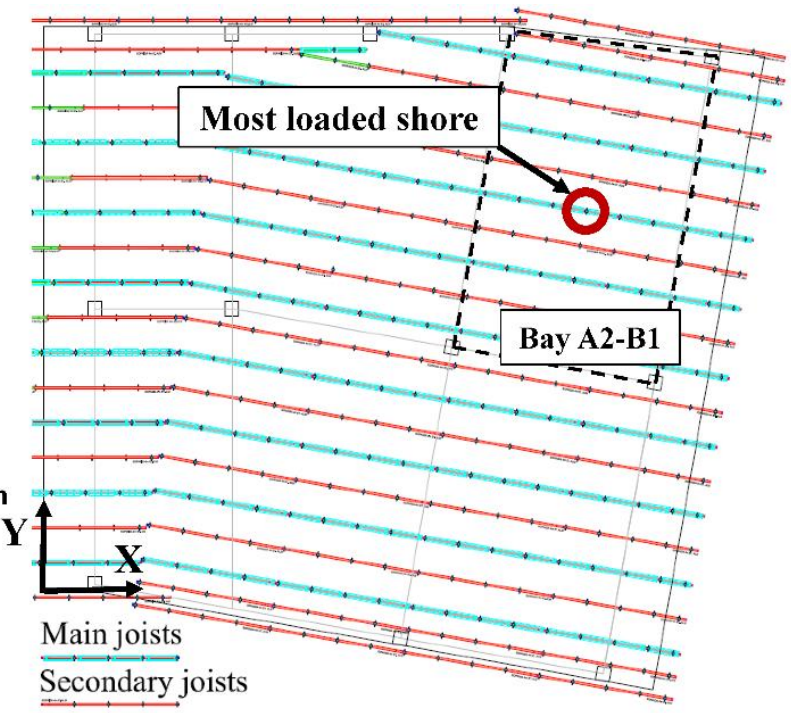

Fig. 2. Building geometry and sketch of the shoring system.

\subsection{Design of shoring system and loading during construction}

According to Adam et al [1], good shoring design should include the correct definition of the permanent and live loads during construction and the use of a calculation tool or method to properly estimate load transmission between slabs and shores. At the present time there is no consensus among the international codes and recommendations as to the live loads on slabs during construction; for example, the ACI [29] suggests a minimum value of $2.4 \mathrm{kN} / \mathrm{m}^{2}$, whereas the Australian standard [30] gives a value of $1.0 \mathrm{kN} / \mathrm{m}^{2}$. On the other hand, Eurocode 1 [31] recommends an overload of $1.5 \mathrm{kN} / \mathrm{m}^{2}$ consisting of $1.0 \mathrm{kN} / \mathrm{m}^{2}$ due to personnel and $0.5 \mathrm{kN} / \mathrm{m}^{2}$ due to shoring equipment. In the present study, the construction live loads in Eurocode 1 were adopted for consistency with the design of the building structure (Eurocode 2). The weight of the structure and shoring were considered to be as permanent loads. Load safety factors for persistent and transient situations were 1.35 and 1.50 for permanent and live

Calderón et al's simplified method [5] and improvements suggested by Buitrago et al [6,7] were used to estimate the loads transmitted between the slabs and shores. This approach has 
been shown to give better predictions than any other method available. An optimisation design

134 approach was then followed using Buitrago et al's criterion [33] to check the construction process which included checking whether the slabs could carry the loads and also checking that

136 the axial load in the shores is below their allowable design load, in which case the construction

137 process considered would be considered as valid.

138 In this work the SCS construction process was adopted (see Fig. 1) consisting of three successively shored floors (two cleared and one totally shored) and clearing of $50 \%$ of the shores (belonging to the secondary joists, as seen in Fig. 2). A standard spacing between joists and between shores was adopted which was equal to $1 \mathrm{~m}(2 \mathrm{~m}$ between joists on the cleared

142 floors) and a new slab was poured every 7 days. This construction sequence was adopted

143 following standard current construction practice [1]. Such cases generally result in high axial

144 loads in the shores which is a highly unfavourable situation to look at notional member removal

145 or local failure of the shoring elements. The maximum axial loads are carried by the shores 146 connected to the foundation/ground during the pouring of the top floor slab connected by shores 147 to the foundations [7,34]. The different structural failure scenarios analysed in sections 3 and 1484 are defined for this most unfavourable construction phase.

149 For the building investigated, the maximum axial load on the shores developed after the pouring of the third-floor slab when the first and second floor slabs were 14 days and 7 days old respectively. The position of the most heavily loaded shore in Bay A2-B1 is shown in Fig.

152 2. The maximum axial load was $47.6 \mathrm{kN}$ which was estimated using the refined approach 153 proposed by Buitrago et al [6] based on the proposal by Calderón et al [5]; a standard shore of $15447.7 \mathrm{kN}$ strength was finally adopted using the design catalogue [35] from a leading international formwork company. It was also verified that all the slabs could carry the loads

156 during all the construction phases. A plan view of the designed shoring system is shown in Fig.

157 2. The mechanical characteristics of the shoring system elements were as follows: 
- Shores: $1.85 \mathrm{~cm}^{2}$ tubular steel cross-section with an elastic modulus of $210 \mathrm{GPa}$.

- Joists: $4.35 \mathrm{~cm}^{2}$ hollow rectangular cross-section with an elastic modulus of $210 \mathrm{GPa}$.

- Formwork boards: $2.7 \mathrm{~cm}$ thick wooden boards with an elastic modulus of $10 \mathrm{GPa}$.

\section{Description of the Finite Element model}

A nonlinear dynamic finite element analysis was carried out in this work using LS-DYNA software [36] with an explicit algorithm in the time domain to solve the equations of motion considering material and geometrical non-linearities. The FE model included the RC flat slab structure, shores and joists during construction. The analysis focused on the most unfavourable construction phase with the highest loads on the shores corresponding to the pouring of slab number three using SCS with two cleared floors and one fully shored as shown in Fig. 3. The FE model of the RC structure had been previously validated by Olmati et al [16] in a separate study on punching shear in slab/column joints due to accidental events. This FE model provided similar results of bending moments and deflections to that reported in CS report [28] for an elastic analysis with a quasi-static load combination used in design.
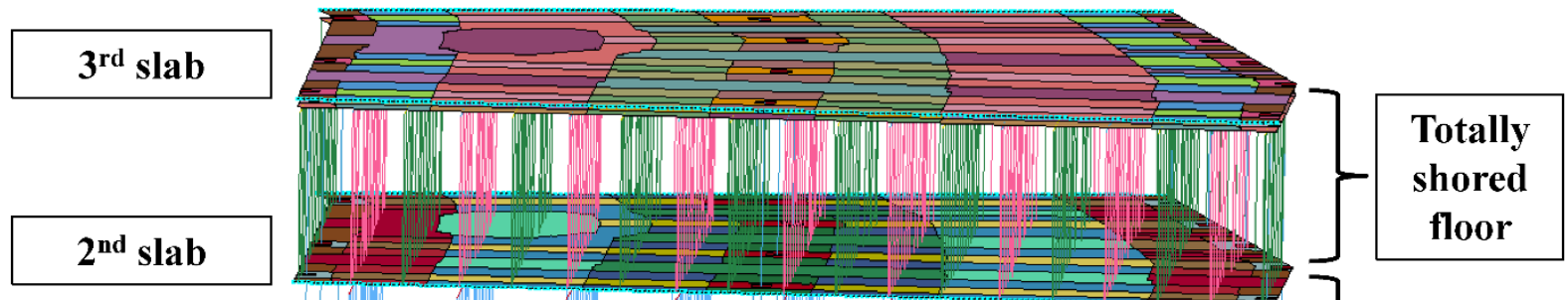

Fig. 3. Modelling of the structure.

In the FE model, concrete slabs were modelled using Hughes-Liu shell elements [36] as 
177 resultant beam elements [36] were used for the columns, stiffly connected to slabs and fully

178 fixed in the foundations. The defined finite elements considered cracking and crushing, as well

179 as yielding, hardening, softening, stiffness degradation due to cyclic loads and fracture of the

180 reinforcement steel as specified in Eurocode $2[16,25]$. Further details of the simulation can be

181 found in Olmati et al [16]. In the present study, involving the simulation of a building under

182 construction, the mechanical properties of the concrete were modified from one slab to another

183 in order to take into account the different curing times; simplified expressions in Eurocode 2

184 [25] were adopted for this. For example, the compressive strength of the first and second slabs

185 shown in Fig. 3 were $34.25 \mathrm{MPa}$ and $29.58 \mathrm{MPa}$ respectively corresponding to the concrete

186 strength at 14 and 7 days and considering a mean temperature of $20^{\circ} \mathrm{C}$ and a cement of class

187 N. Young Modulus is automatically considered on the model using the expressions of EC-2

188 [25] for the different concrete strength of the slabs. Eq.1, Eq.2 and Eq.3 are the expressions

189 from EC-2 [25] for the main mechanical properties of concrete at different ages: compressive

$190\left(f_{\mathrm{cm}}\right)$ and tensile $\left(\mathrm{f}_{\mathrm{ctm}}\right)$ strength and young modulus $\left(\mathrm{E}_{\mathrm{cm}}\right)$, respectively. The different parameters

191 can be obtained from EC-2 [25].

192

193

194 modulus (300 $\mathrm{MPa})$ to simulate fresh concrete. Table 1 summarizes the main mechanical parameters used in the model. 
Table 1. Mechanical parameters of slabs and shoring system.

\begin{tabular}{llc} 
Element & Parameter & Value \\
\hline \multirow{3}{*}{$1^{\text {st }}$ slab } & Compressive strength at 14 days $\left[\mathrm{f}_{\mathrm{cm}, 14}\right]$ & $34.25 \mathrm{MPa}$ \\
& Tensile strength at 14 days $\left[\mathrm{f}_{\mathrm{ctm}, 14}\right]$ & $2.61 \mathrm{MPa}$ \\
& Young modulus at 14 days $\left[\mathrm{E}_{\mathrm{cm}, 14}\right]$ & $31.83 \mathrm{GPa}$ \\
\hline \multirow{3}{*}{$2^{\text {nd }}$ slab } & Strength at 7 days $\left[\mathrm{f}_{\mathrm{cm}, 7}\right]$ & $29.58 \mathrm{MPa}$ \\
& Tensile strength at 7 days $\left[\mathrm{f}_{\mathrm{ctm}, 7}\right]$ & $2.25 \mathrm{MPa}$ \\
& Young modulus at 7 days $\left[\mathrm{E}_{\mathrm{cm}, 7}\right]$ & $30.46 \mathrm{GPa}$ \\
\hline \multirow{3}{*}{ Shores } & Strength & $47.70 \mathrm{kN}$ \\
& Area & $1.85 \mathrm{~cm}^{2}$ \\
& Young Modulus & $210 \mathrm{GPa}$ \\
\hline \multirow{2}{*}{ Joists } & Area & $4.35 \mathrm{~cm}$ \\
& Young Modulus & $210 \mathrm{GPa}$ \\
\hline \multirow{2}{*}{ Formwork boards } & Thickness & $2.70 \mathrm{~cm}$ \\
& Young Modulus & $10 \mathrm{GPa}$ \\
\hline
\end{tabular}

The shores were modelled using Hughes-Liu beam elements with cross section integration

205 [36], which allows the failure of these elements to be considered. The piecewise linear plasticity material model [36] was used to consider linear elastic shore behaviour until yielding point (elasto-plastic behaviour). A very low ultimate plastic strain (1E-6) was adopted in order to have member failure soon after yielding. All the shores had compatibility of displacements and rotations (as hinges) at the lower node (slab-shore connection) and at the upper node (joist-

210 shore connection). On the ground floor the lower nodes of the shores had restricted 211 displacements and free rotations.

212 The joists were modelled with Belytschko-Schwer resultant beam elements [36] and the

213 formwork of the last floor with Hughes-Liu shell elements [36], both with linear and elastic

214 behaviour. Connection between joists and slabs, joists and formwork boards, and formwork

215 boards and slabs were modelled as contacts. Joists-slab and joists-formwork connections were 216 modelled using Automatic_Node-to-Surface contact [36], whereas formwork-slab connection 217 was by Automatic-Surface-to-Surface contact [36]. In all cases, a static coefficient of friction 218 of 0.45 and a dynamic coefficient of friction of 0.20 was considered [37,38]. Although these 
219 values largely depend on the conditions of the materials (e.g. oxidation, deterioration) and the 220 type of material used [37], a sensitivity study carried out with these parameters showed that 221 any variations had almost no effect on the results.

222 The dead load (DL) was applied in the FE model as the self-weight of the different elements: density of $25 \mathrm{kN} / \mathrm{m}^{3}$ for concrete, $5.3 \mathrm{kN} / \mathrm{m}^{3}$ for wood and $78.5 \mathrm{kN} / \mathrm{m}^{3}$ for steel. The live load (LL) was also applied as a uniformly distributed mass on the slab. A characteristic value of the live load equal to $1.0 \mathrm{kN} / \mathrm{m}^{2}$ due to personnel was adopted (EN 1991-1-6:2005 [31]), since the self-weight of the shoring system is automatically taken into account by the FE model. The frequent load combination was used in the analysis (i.e. DL+0.5LL) corresponding to accidental load combinations in accordance with Eurocode [32] and most international codes using the alternative load path method. The factor for frequent load value of 0.5 was taken directly from Eurocode [32] lacking a more refined value in design codes for falsework under accidental situations. This is a contentious issue for shoring design where members are generally stressed nearer the permissible working stress and the variability of the imposed loads is lower than for permanent structures [8]. In the FE analyses, the gravity acceleration was introduced gradually over time using a ramp function within $t=0 \mathrm{~s}$ and $\mathrm{t}=0.8 \mathrm{~s}$, similarly to Olmati et al [16]. This was followed by a time interval of stabilization and the introduction of a sudden local failure scenarios as described in Section 4.

\section{Local failure scenarios and results}

This section defines the different local failure scenarios of some of the shoring components to study their effects on the behaviour of the structure-shoring system. This is relevant since according to a recent study by Buitrago et al [10], shore failure is the principal cause of the collapse of buildings under construction. These failures are mainly due to: loads higher than allowable design loads on the shores, improper shore installation or lack of shore bracing. Table 
2442 summarizes the local failure scenarios defined, and the possible causes they may represent.

245 Table 2 also gives the estimated probability of occurrence of a building collapse under

246 construction due to these situations (results are based on a field survey) which justify further

247 the adoption of the scenarios considered in this work. The probability of occurrence of each

248 cause was quantified in direct proportion to the number of times the cause was cited or appeared

249 in the different accident reports studied in the previous work [10].

250 Table 2. Definition, causes and probability of different failure scenarios.

\begin{tabular}{|c|c|c|c|}
\hline Scenarios & Definition & Possible causes & $\begin{array}{c}\text { Probability of } \\
\text { occurrence }^{\mathrm{a}}\end{array}$ \\
\hline \multirow{4}{*}{$\begin{array}{l}1^{\text {st }}, 2^{\text {nd }} \text { and } \\
3^{\text {rd }} \text { scenarios }\end{array}$} & \multirow{4}{*}{$\begin{array}{l}\text { Instant removal of the } \\
\text { most loaded shore, a } \\
\text { joist and a complete } \\
\text { shore line respectively, } \\
\text { in a single time step } \\
\left(\Delta \mathrm{t}=10^{-6} \mathrm{~s}\right)\end{array}$} & $\begin{array}{l}\text { Non-expected loads higher than } \\
\text { allowable load of shores }\end{array}$ & $18 \%$ \\
\hline & & Poor installation/foundation failure & $3 \%$ \\
\hline & & $\begin{array}{l}\text { Impacts on shores or impact of a } \\
\text { heavy load }\end{array}$ & $3 \%$ \\
\hline & & Operator decision & No data available \\
\hline \multirow{8}{*}{$4^{\text {th }}$ scenario } & \multirow{8}{*}{$\begin{array}{l}\text { Wrong election of } \\
\text { shores with less capacity } \\
\text { than necessary }\end{array}$} & $\begin{array}{l}\text { Construction process is not } \\
\text { considered in the design stage }\end{array}$ & $26 \%$ \\
\hline & & Lack of inspection & $18 \%$ \\
\hline & & Construction without permission & $18 \%$ \\
\hline & & $\begin{array}{l}\text { Deficient estimation of shore loads } \\
\text { which produce loads higher than } \\
\text { their allowable load (wrong design) }\end{array}$ & $18 \%$ \\
\hline & & $\begin{array}{l}\text { Sub-standard materials or } \\
\text { workmanship }\end{array}$ & $15 \%$ \\
\hline & & $\begin{array}{l}\text { None or only one structural } \\
\text { engineer }\end{array}$ & $6 \%$ \\
\hline & & Lack of codes or mandatory laws & $6 \%$ \\
\hline & & $\begin{array}{l}\text { Formwork company send a wrong } \\
\text { kind of shore with the same length }\end{array}$ & No data available \\
\hline
\end{tabular}

$251 \quad{ }^{a}$ According to Buitrago et al [10]

252 The local failure scenarios considered followed the conventional notional member removal

253 approach used traditionally for permanent structures to assess whether the structure can

254 develop alternative load paths after local damage [16,20,26,27,39,40]. The aim of this study

255 was to determine the effects of sudden failure of one or more ground-floor shores, which carry

256 the highest loads when the third floor is poured, with two cleared floors and one fully shored.

257 The risk of local failure is high in this situation since the shores operate close to their allowable

258 load. The removal of the most loaded elements in the shoring system was adopted because 
259 these elements are usually installed near the centre of the bay, where the slabs might be strongly

260 affected because of the loss of its support during construction in the zone of maximum

261 displacement. Additionally, as the expected key of alternate load path in accidental events

262 during construction is the ability of distributing loads with the help of the load transmission

263 between slabs and shores, these failures scenarios were considered as critical situations with

264 greater probability of occurrence, for the first approach to the study of sudden failure of shoring

265 elements during construction.

266 In this work, the local damage and the study on the behaviour of the shore-structure system

267 focuses on a representative bay (A2-B1) as shown in Fig. 4. Four different local failure

268 scenarios of the most heavily loaded shores were considered in A2-B1: 1) failure of the most

269 heavily loaded shore (see Fig. 2 and Fig. 4b), 2) failure of the joist over this shore (see Fig. 4c),

270 3) failure of the complete shore line including this shore (see Fig. 4d) and 4) incorrect selection

271 of shores. The following subsections give the results obtained for the scenarios considered,

272 including an analysis of the behaviour and the alternative load paths developed in the structure

273 to re-distribute the loads after local failure. The RC structure was checked for flexure and

274 punching shear in accordance with Eurocode 2 [25] in the time history analysis to assess

275 potential damage in the concrete slabs. 

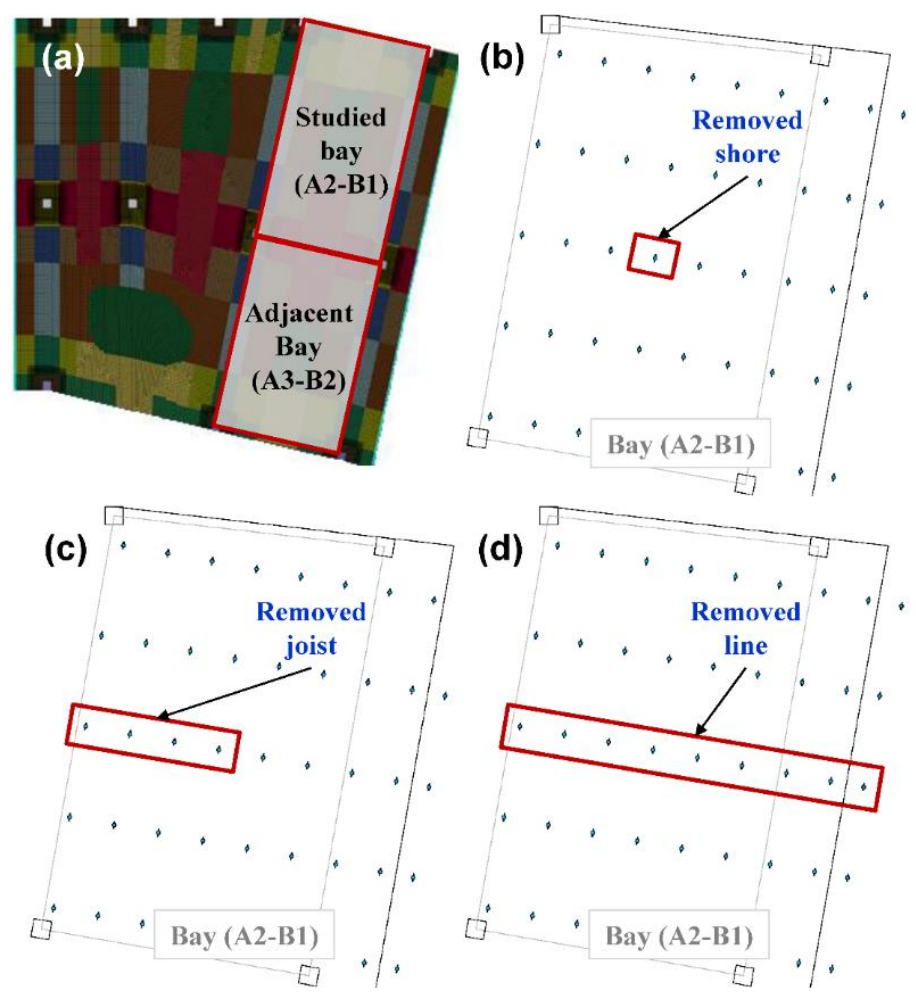

Fig. 4. Position of the bay under study (a) and scenarios of sudden failure of ground-floor shores (b, c and d).

\section{8}

279

\section{1. $1^{\text {st }}$ scenario: failure of the most heavily loaded shore}

Fig. 5 summarizes the FE results obtained describing the structural behaviour after the sudden removal of the most heavily loaded shore supporting the first slab. Fig. 5a shows the loads carried by the shores supporting the first and second slabs on the point at which the shore was removed (see Fig. 4b). During the stabilization period (between $t=0.8 \mathrm{~s}$ and $\mathrm{t}=1.3 \mathrm{~s}$ ) the axial load in the most heavily loaded shore is around $34 \mathrm{kN}$ which is consistent to that obtained in Section 2.2 for the design of the shoring system. This validates further both the FE model and the simplified method in $[5,6]$. After the sudden shore removal at $t=1.3 \mathrm{~s}$ the load in the eliminated shore drops to zero as expected whereas in the shore immediately above the removed one the load only reduces slightly due to the small increase of the vertical deformation of the first slab. Fig. $5 b$ shows the small increment in the displacement of the first and second slabs at the position of the most heavily loaded shore (shown as thick lines). This displacement is higher in the first floor, which confirms the slight reduction of the compression load on the shore supporting the second floor. 
Overall the obtained response was significantly different to cases of column removal in buildings leading to progressive collapse where the axial load in all the columns above the failure). In the problem under consideration, the development of alternative load paths kept a significant contribution of the shores on the floors above the local failure. This behaviour also Fig. 4a) as shown in Fig. $5 b$.

a

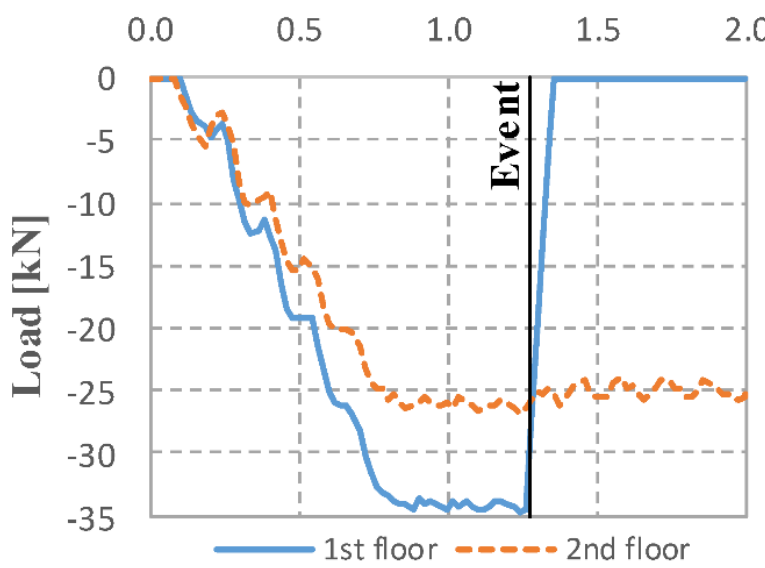

C

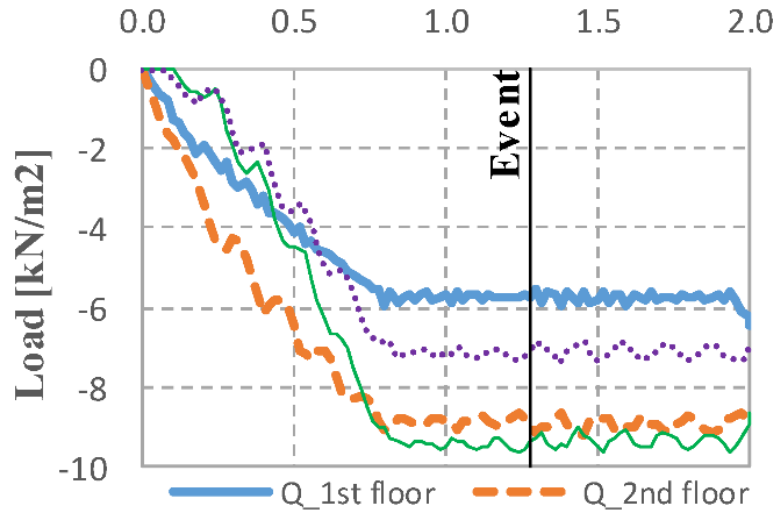

299 b

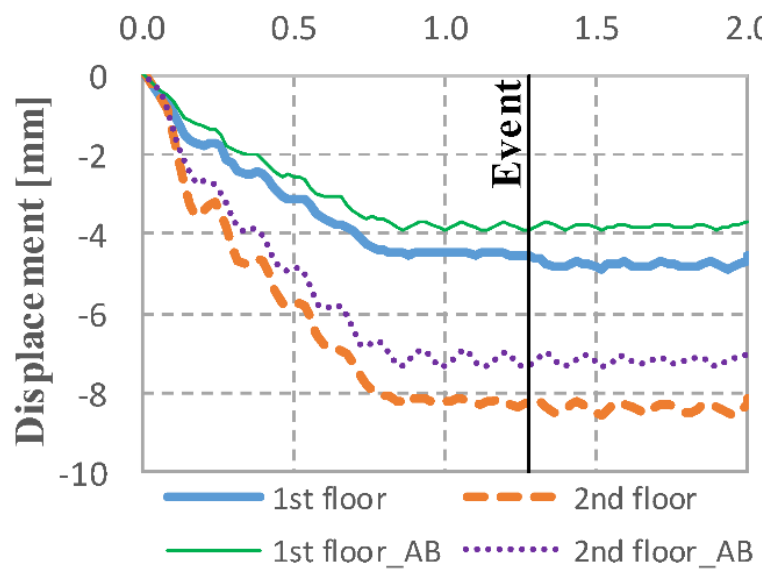

d

Dis place ment [mm]

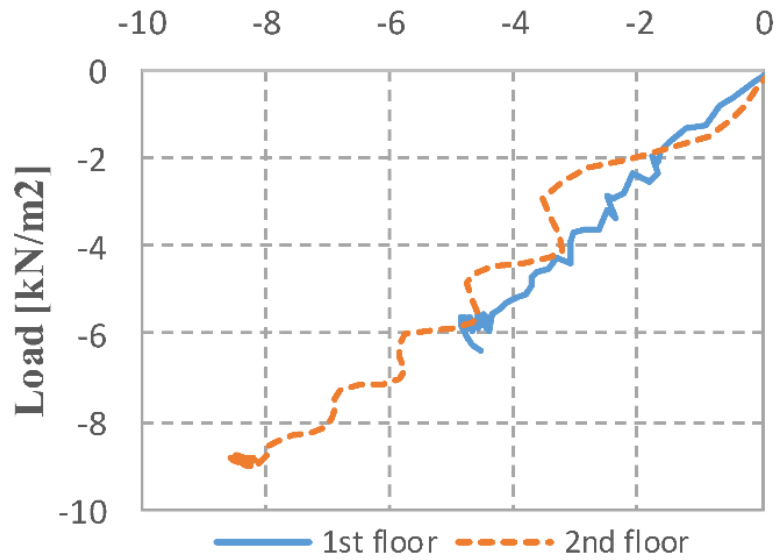

Fig. 5. Patterns of the behaviour of slabs and shoring in the first failure scenario: a) load received by the shores supporting the first and second slabs coinciding with the position of the eliminated shore, b) displacement of

first and second slabs in the position of the eliminated shore in the studied bay and adjacent bay AB, c) loads on slabs $(\mathrm{Q})$ and shoring system (S) for the first and second floors, and d) load-displacement curve of the first and second floor slabs in the position of the eliminated shore. 
After analysing the local displacements and axial loads on the shores, the overall behaviour was analysed (sum of vertical reactions for each floor corresponding to the shores and the columns). Therefore for each floor, the loads per unit surface $\left(\mathrm{kN} / \mathrm{m}^{2}\right)$ carried by the shoring system (S) and the slabs (Q) were calculated. In Fig. 5c it can be seen that the sudden event consisting of the removal of the most heavily loaded shore under the first slab does not alter the structure's overall behaviour. This can also be seen in Fig. 5d, which shows the slab loaddisplacement curve of the first two floors considering the slab displacement at the position of the most heavily loaded shore. The slope of this curve is constant, confirming the linear behaviour of the slabs and showing that they have not been affected by the event.

Fig. 5d also suggests that the local failure did not result on slab cracking. The moments calculated from the FE model are far from the cracking moment $(51.6 \mathrm{kN} \cdot \mathrm{m} / \mathrm{m}$ for the first and $41.3 \mathrm{kN} \cdot \mathrm{m} / \mathrm{m}$ for the second slab), which confirms the linear behaviour in Fig. $5 \mathrm{~d}$. The slabs also comply satisfactorily with flexural and punching shear requirements in Eurocode 2 [25] for the accidental load combination considered. It can be concluded that after the sudden removal of the most heavily loaded shore, the structure remains undamaged and is able to efficiently seek alternative load paths (i.e. loads are shared between slabs one and two with loads Q almost unaltered). No dynamic amplification was obtained in the analysis.

\section{2. $2^{\text {nd }}$ Scenario: failure of the joist on the most loaded shore}

Fig. 6 summarizes the results from the analysis corresponding to the sudden removal of the

324 joist over the most heavily loaded shore under the first slab (see Fig. 2 and 4c). After the extreme event at $\mathrm{t}=1.3 \mathrm{~s}$, the eliminated and most heavily loaded shore drops to zero as expected whereas in the shore above, supporting slab 2, the load reduces $2.5 \mathrm{kN}(10 \%$ reduction). As in the first scenario (see Section 4.1), the reduced load on the shore under slab 2 is due to the increased deformation of slab 1 after the local failure. The thickest lines in Fig. 
position of the most heavily loaded shore under the first slab. The displacement is higher in

331 slab 1, which explains the reduction in load of the shore supporting slab 2. Fig. 6b also shows

332 that the sudden event has no effect on the adjacent bay (AB) A3-B2.

a

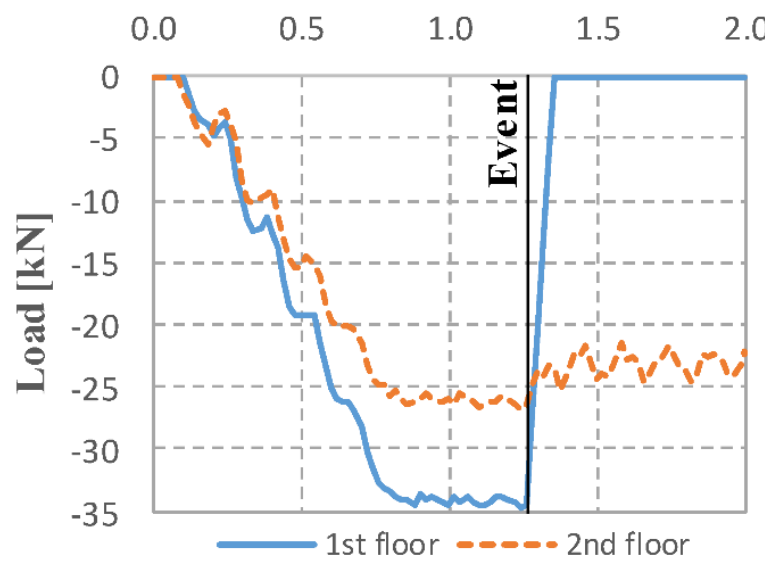

C

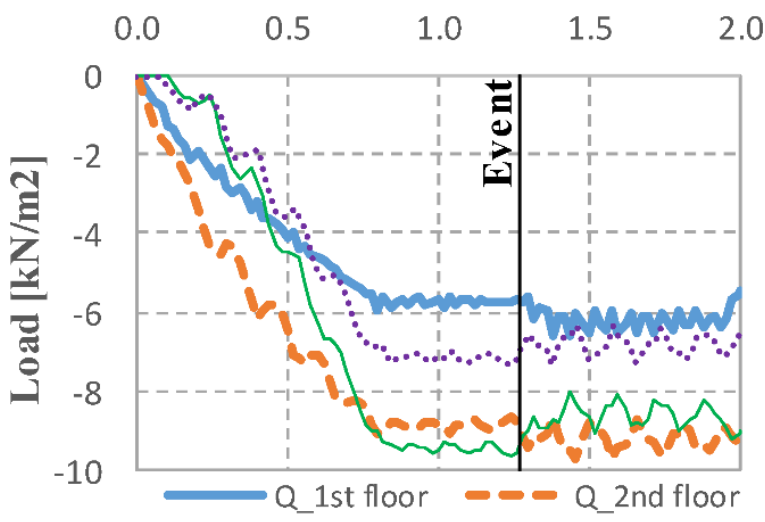

333

334

335

336

337

338

339

340

341

342 b

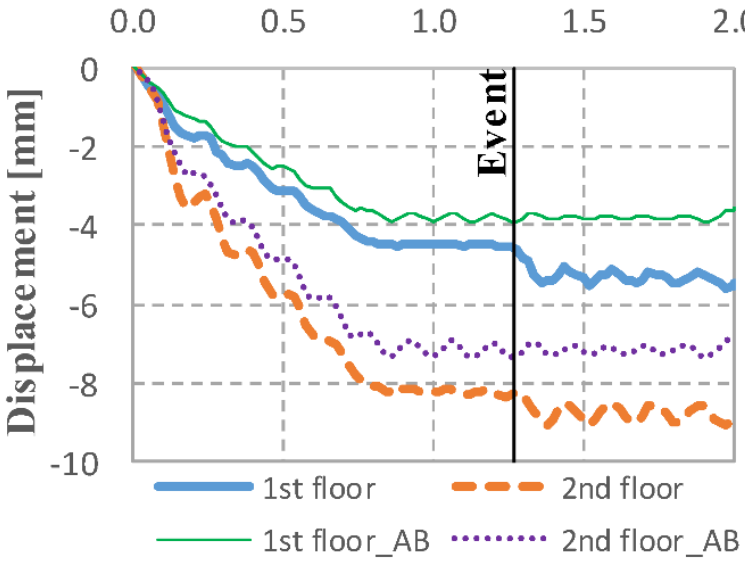

d Dis placement [mm]

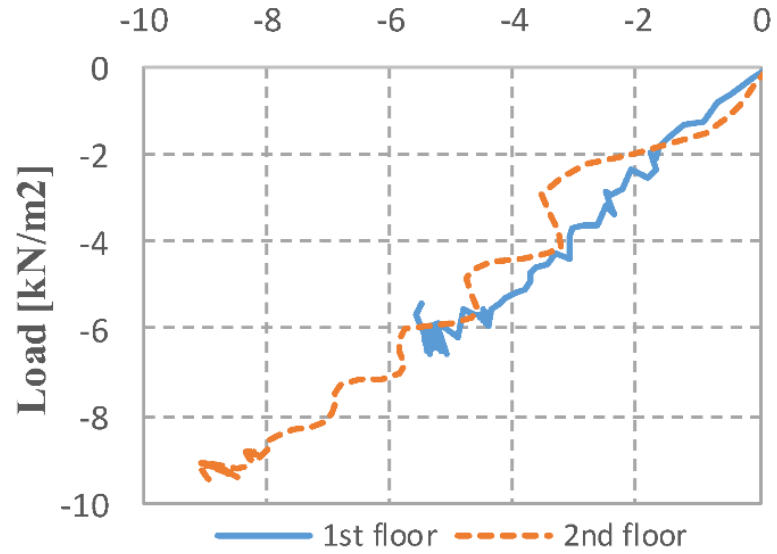

Fig. 6. Patterns of the behaviour of slabs and shoring in the second failure scenario: a) load received by the shores supporting the first and second slabs coinciding with the position of the most heavily loaded shore supporting the first slab, b) displacement of slabs 1 and 2 in the position of the most heavily loaded shore supporting the first slab in the studied bay and adjacent bay $A B, c)$ loads on slabs $(Q)$ and shoring system $(S)$ for the first and second floors, and d) load-displacement curve of the first and second floor slabs in the position of the most heavily loaded shore supporting the first slab.

A similar analysis of the overall structural behaviour was carried out for each floor looking at the loads per unit surface $\left(\mathrm{kN} / \mathrm{m}^{2}\right)$ carried by the shores $(\mathrm{S})$ and slabs $(\mathrm{Q})$. In Fig. 6c it can be seen that the sudden event had no effect on the overall structural behaviour. Due to the 
higher deformability of the shoring system under slab 1 , the load carried by this slab increased

344 (about $0.6 \mathrm{kN} / \mathrm{m}^{2}$ more) whereas the load carried by the shores reduced (about $0.9 \mathrm{kN} / \mathrm{m}^{2}$ less).

345 The higher deformability of the shores under slab 1 also caused a higher deformability in the 346 elements supporting slab 2 (slab 1 and shores under slabs 1 and 2). Thus, the load carried by 347 slab 2 was also higher (about $0.3 \mathrm{kN} / \mathrm{m}^{2}$ more) whereas the load carried by the shores under slab 2 was lower (about $0.3 \mathrm{kN} / \mathrm{m}^{2}$ less). Fig. $6 \mathrm{~d}$ shows the slab load-displacement curve of slabs 1 and 2 at the position of the most heavily loaded shore under slab 1. Similarly as in the first scenario, the curve has a steady slope and, even though there is a slight increase in the displacements and load carried by the slab after local failure, the relationship is still linear.

Fig. 7 gives the most unfavourable bending moments obtained from the FE model in the bay investigated (moment $\mathrm{Mx}$ in the direction of longer span). This figure shows the areas in the slab liable to cracking (cracking moment of $51.6 \mathrm{kN} \cdot \mathrm{m} / \mathrm{m}$ and $45.3 \mathrm{kN} \cdot \mathrm{m} / \mathrm{m}$ for slabs 1 and 2 respectively). The positive moments of slabs 1 and 2 increase after the local failure whereas the negative moments remain constant (see Fig. 7). The most severe case of cracking was found at mid-span in slab 2 at the position of the failed joist in slab 1 (see Fig. 4c), although the total cracked zone is very localised. The slabs satisfactorily complied with the flexural and punching shear requirements specified in Eurocode 2 [25] for the accidental load combination considered.

It can be concluded from this local failure scenario that similarly as in the first scenario the structure is able to efficiently seek alternative load paths without failing. However, in this scenario greater cracking was obtained, particularly in slab 2 after the sudden event, which could have a negative effect on serviceability limit state performance (e.g. long-term deformations, crack widths). The area affected by cracking is not significant so the level of consequence could still be classified as "minimal" according to IStructE risk manual [41] or "very low" according to EN 1991-1-7 [9]. 

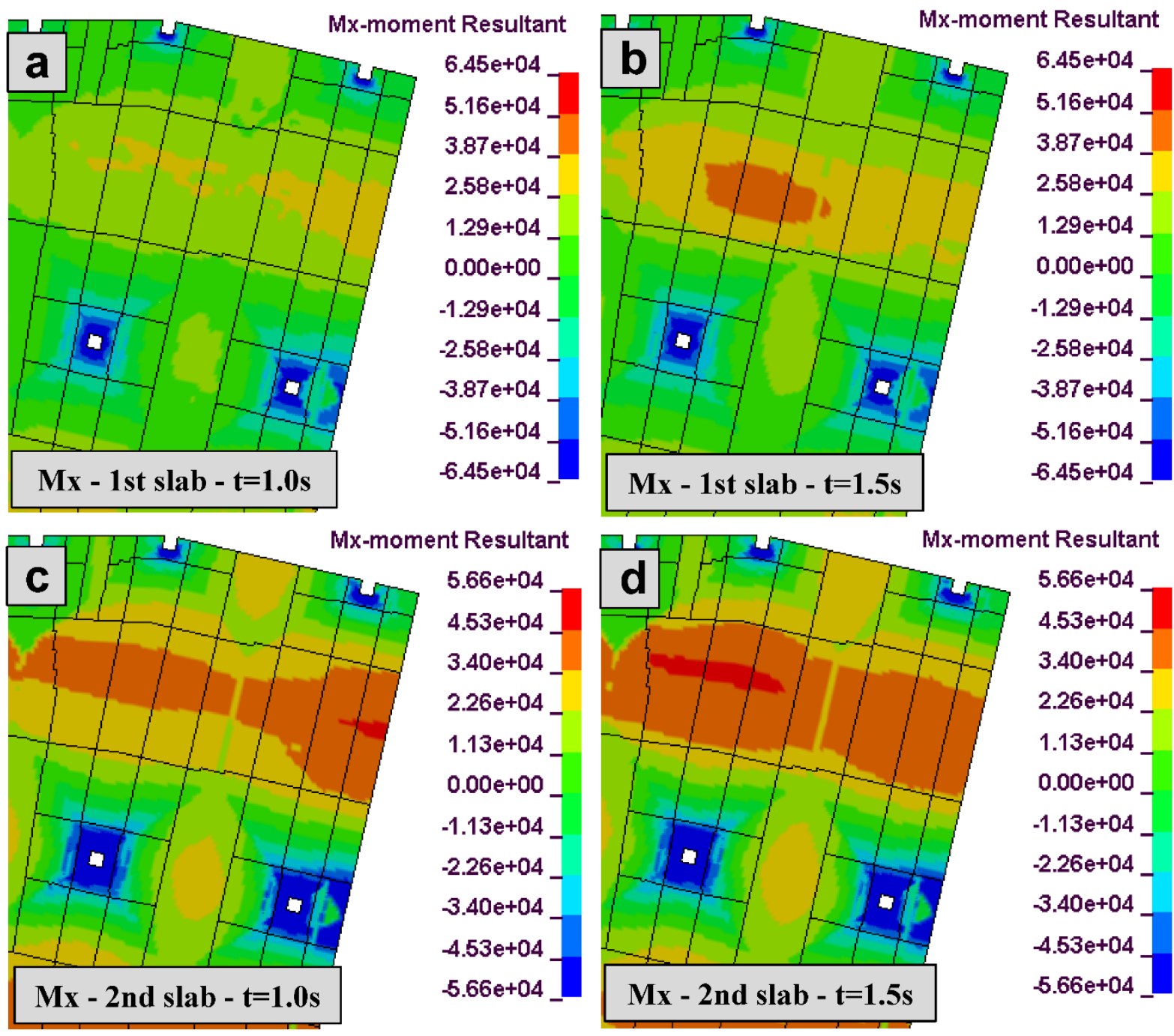

Fig. 7. Bending moments of first ( $a$ and $b$ ) and second ( $c$ and d) slabs before (a and $c$ ) and after ( $b$ and d) the accidental event for the second scenario (units in $\mathrm{N} \cdot \mathrm{m} / \mathrm{m}$ ).

\section{3. $3^{\text {rd }}$ Scenario: failure of the complete shore line on the most loaded shore}

Fig. 8 shows the sudden failure (at $\mathrm{t}=1.1 \mathrm{~s}$ ) of a complete shore line (see Fig. $4 \mathrm{~d}$ ) causing the progressive collapse of all the other shores. As can be seen from the sequence of images in

Fig. 8 (at $0.1 \mathrm{~s}$ intervals), when the central line of shores under slab 1 is removed there is a chain reaction in all the shores at this level in which all collapse. In each step of the sequences in Fig. 8 , the shores that fail in the following step (i.e. ultimate strength is reached) are shown in red. In this case, when a large number of shores fail between $\mathrm{t}=1.1 \mathrm{~s}$ and $\mathrm{t}=1.2 \mathrm{~s}$ the shoring under slab 1 becomes more flexible, increasing the deformation of this slab and the loads on the remaining shores around those that have previously failed. This increase in deformations can 
381 collapse one after the other. The deformation of the structure before and after the sudden event

382 is shown in Fig. 9 for $t=1.0 \mathrm{~s}$ (Fig. 9a) and $\mathrm{t}=1.5 \mathrm{~s}$ (Fig. 9b), in which the collapsed shores are 383 not shown.

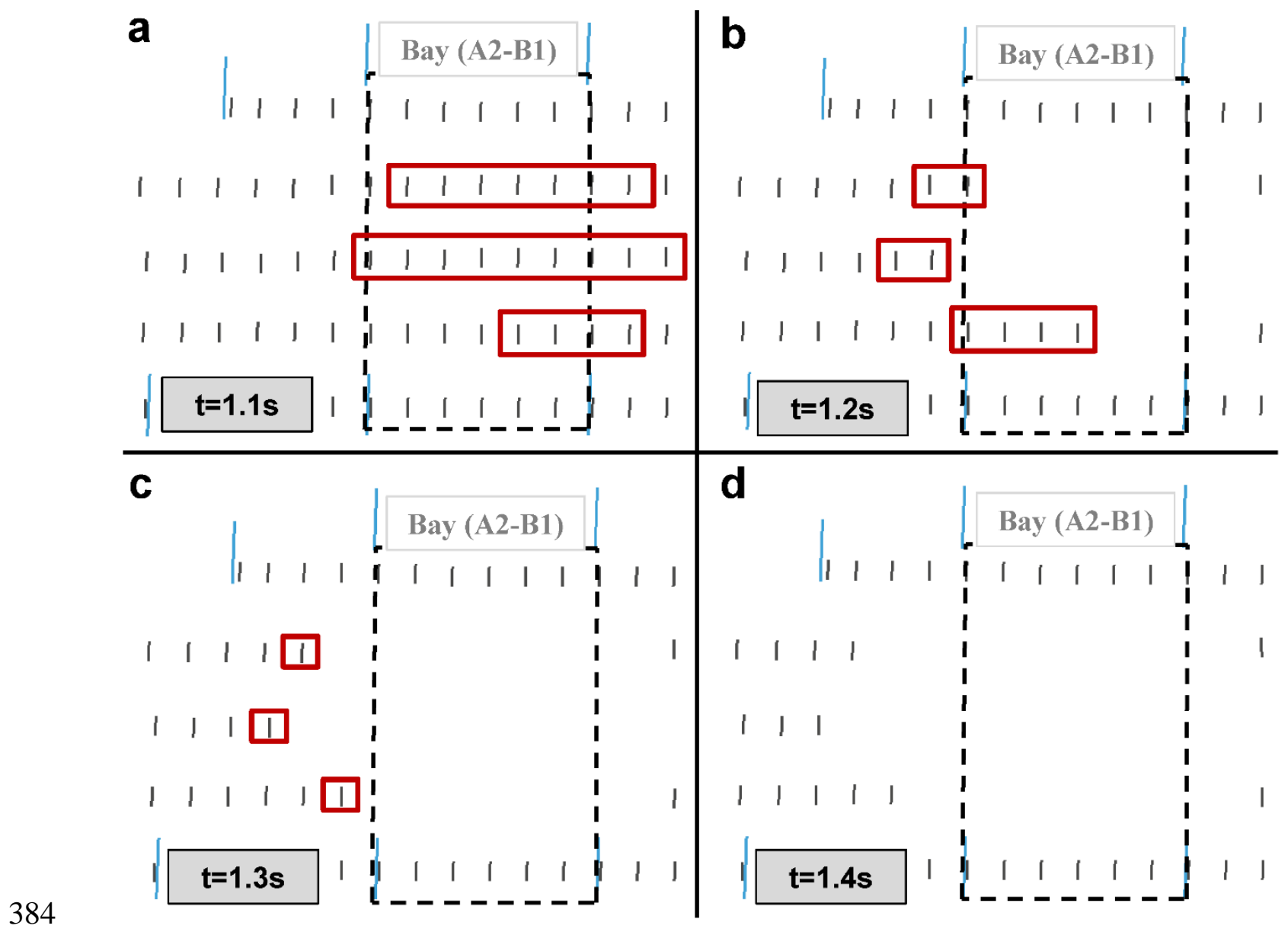

Fig. 8. Progressive collapse of the shoring system in the 3rd scenario.
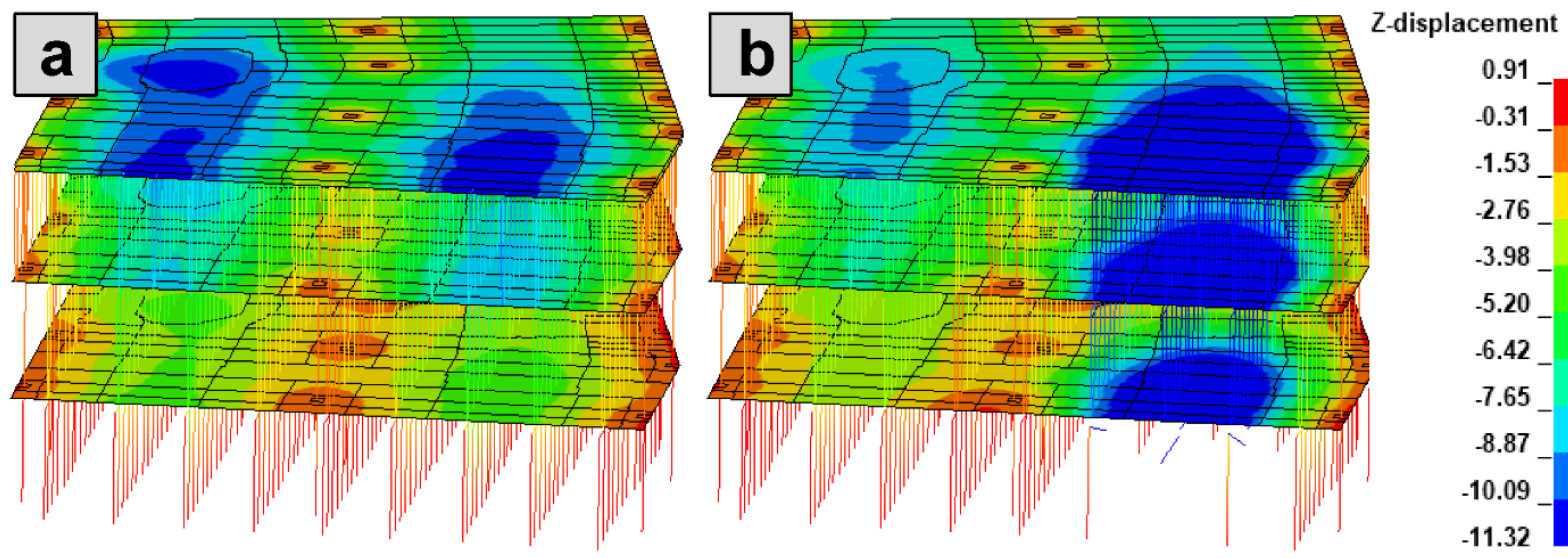

Fig. 9. Structure before (a) and after (b) the sudden event (units in $\mathrm{mm}$ ). Collapsed shores are not shown. 
Fig. 10 shows the main results obtained describing the structural behaviour. As can be seen in Fig. 10a, after the extreme event at $\mathrm{t}=1.1 \mathrm{~s}$ in the position of the most heavily loaded shore under slab 1 (Fig. 2), the load on the shore under slab 1 drops to zero and that on the shore under slab 2 is gradually reduced (around 56\% reduction) during the gradual collapse of the shoring system. As occurred in Scenarios 1 and 2 (Sections 4.1 and 4.2) this reduction of the load in the shore under slab 2 in the position under study is due to the increased deformation of slab 1 after the failure of a complete shore line. The thickest lines in Fig. 10b show how the progressive collapse gradually results in a sudden increase of the vertical displacements of slabs 1 (around $9 \mathrm{~mm}$ increase) and 2 (around $8 \mathrm{~mm}$ increase) at the position of the most heavily loaded shore under slab 1 . The deflection is higher in slab 1 , which confirms the reason for the reduced load on the shore under slab 2. Fig. 10b also shows how an extreme event such as that that happened in the bay under study has no effect on the adjacent bay (AB) A3-B2 .

Fig. 10c gives the loads per unit surface $\left(\mathrm{kN} / \mathrm{m}^{2}\right)$ carried by the shoring system $(\mathrm{S})$ and slabs (Q) on each floor. Fig. 10c shows how the overall behaviour of the structure is affected by the extreme event. As the deformability of the shoring under slab 1 is higher, this slab will carry greater load (about $2.5 \mathrm{kN} / \mathrm{m}^{2}$ more) whereas the load carried by the shoring system will reduce (about $5.0 \mathrm{kN} / \mathrm{m}^{2}$ less). In turn, the higher deformability of the shoring system under slab 1 makes the support of slab 2 (consisting of slab 1 and the shoring under slabs 1 and 2) more deformable. The load carried by slab 2 is therefore also higher (about $2.5 \mathrm{kN} / \mathrm{m}^{2}$ more) and the

407 load carried by the shores under this slab is lower (about $2.5 \mathrm{kN} / \mathrm{m}^{2}$ less). Fig. $10 \mathrm{~d}$ gives the 408 load-displacement curve of slabs 1 and 2 in relation to their displacement at the position of the 409 most heavily loaded shore of the ground floor. The slope can be seen to suddenly drop at the start of the collapse of the shoring system. The drastic reduction in the stiffness of the slabs is

411 the first indication of the high level of cracking that develops. 
a

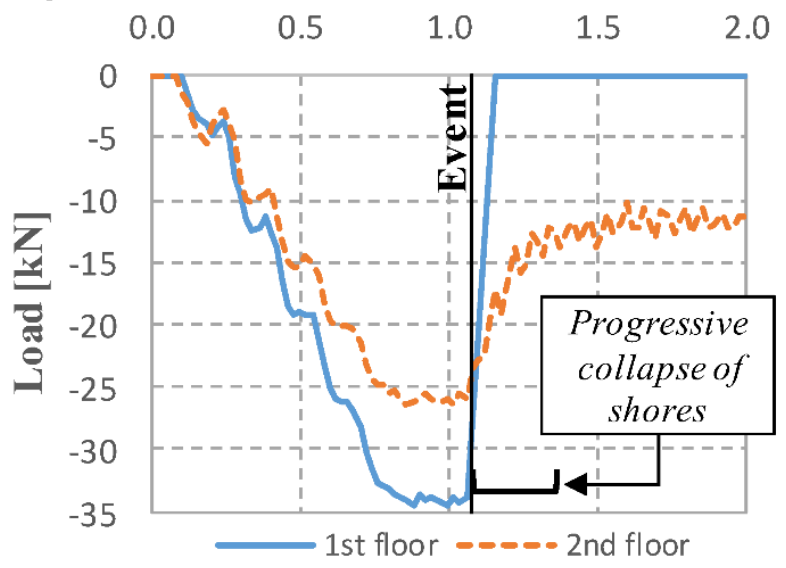

C

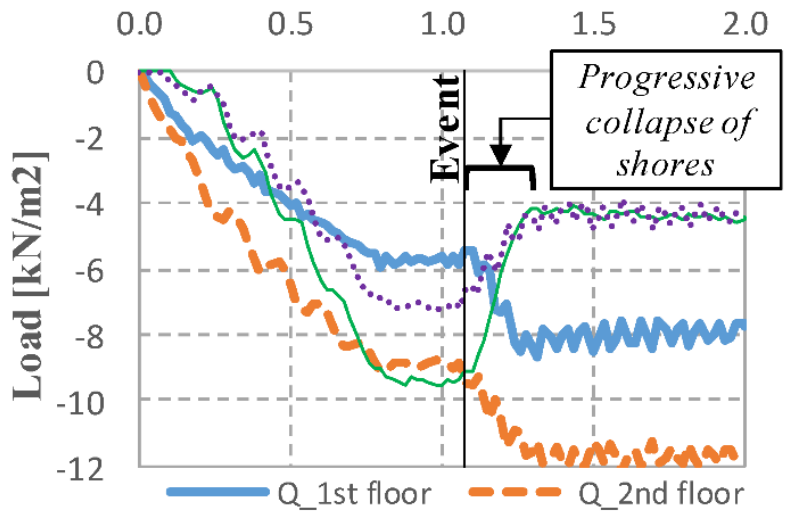

412

413 b

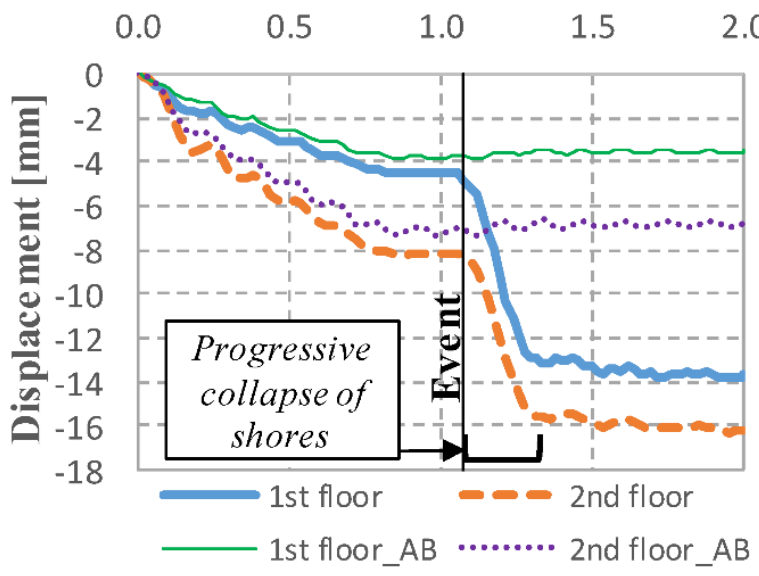

d

Dis place ment [mm]

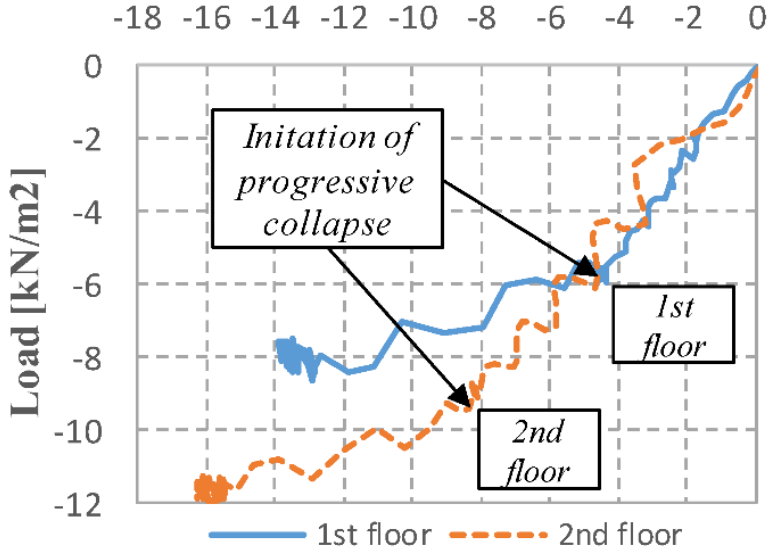

Fig. 10. Patterns of the behaviour of slabs and shoring in the third failure scenario: a) load received by the shores under slabs 1 and 2 at the position of the most heavily loaded ground-floor shore, b) displacement of slabs 1 and 2 at the position of the most heavily loaded ground-floor shore in the bay under study and adjacent bay $\mathrm{AB}, \mathrm{c}$ ) loads on slabs $(\mathrm{Q})$ and shores (S) of first and second floors, and d) load-displacement curve of slabs 1 and 2 at the position of the most heavily loaded ground-floor shore.

Fig. 11 gives the moments obtained from the FE model in the bay under study (A2-B1) on the most unfavourable axis (bending moment Mx along the long span). Both the positive and negative moments in both slabs (see Fig. 11b and Fig. 11d) are higher than before the extreme event (Fig. 11a and Fig. 11c). Fig. 11 shows that the development of cracking at the position of the shore failures (See Fig. 4d) and in the zone close to the columns is severe (the cracking moment is $51.6 \mathrm{kN} \cdot \mathrm{m} / \mathrm{m}$ and $45.3 \mathrm{kN} \cdot \mathrm{m} / \mathrm{m}$ for the first and second slab respectively). The moments along the short span (not shown) also caused severe cracking in the slabs around the 

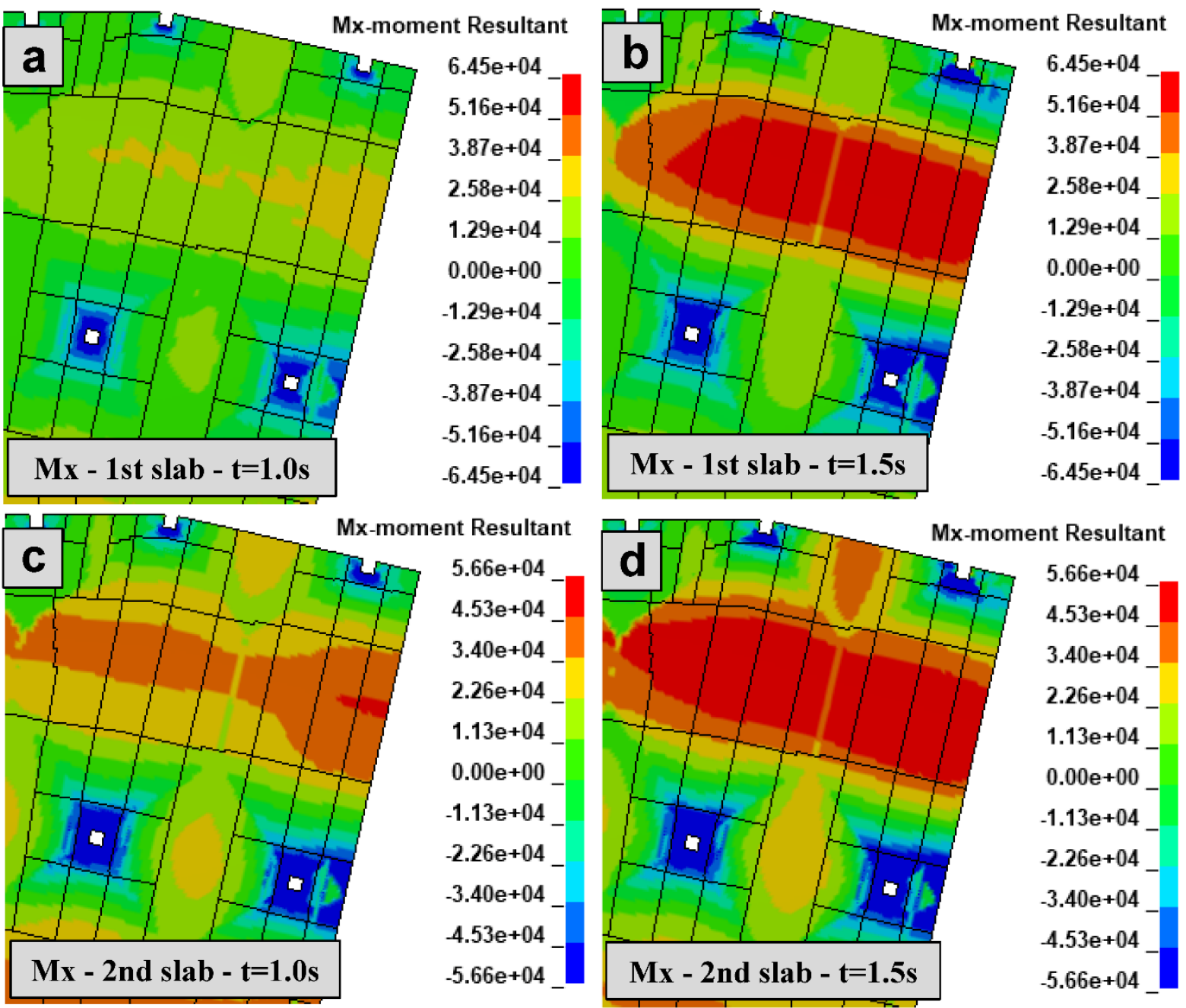

Fig. 11. Bending moments of first ( $a$ and $b$ ) and second ( $c$ and d) slabs before (a and $c$ ) and after ( $b$ and $d)$ the accidental event in the third scenario (units in $\mathrm{N} \cdot \mathrm{m} / \mathrm{m}$ ).

It can be concluded that whilst the local damaged considered resulted in the progressive collapse of the shoring system, the building structure did not fail due to the efficient alternative load paths that could be activated in the shoring-structure system after local failure (i.e. load sharing between slabs 1 and 2 was critical, as seen from their displacements and loads). After the event the slabs carried higher loads (Q) although similar to previous scenarios no dynamic amplification of loads nor deflections was observed from the FE analysis. The high level of slab cracking obtained in this scenario could result in potential serviceability and durability 
issues. In such cases the safety of the structure would need to be assessed in parallel with a cost analysis in order to determine possible repairing measures and whether it should be demolished. The scale of consequence in this case (local permanent structural damage) can be classified as "minor" according to the IStructE systematic risk assessment approach [41] or

441 "low" according to EN 1991-1-7 [9].

\section{4. $4^{\text {th }}$ Scenario: incorrect selection of shores}

In design, incorrect sizing of the shores can occur due to a number of reasons (see Table 2 in Section 4). In this scenario a shore immediately below the strength of those used in the other scenarios (Sections 4.1, 4.2 and 4.3) was used from the same formwork provider [35]. The ultimate strength of this shore was $30.6 \mathrm{kN}$, well below the strength required of $47.6 \mathrm{kN}$ in design. After changing the mechanical characteristics (cross-section and shore ultimate strength) in the numerical model to those of the new shore, Fig. 12 shows how the progressive application of the entire expected load (i.e. quasi-static loading) between $\mathrm{t}=0 \mathrm{~s}$ and $\mathrm{t}=0.8 \mathrm{~s}$ caused the progressive collapse of the shoring system at $\mathrm{t}=0.66 \mathrm{~s}$.

As can be seen in the images at $0.1 \mathrm{~s}$ intervals (Fig. 12), after the start of the collapse all the shores under slab 1 begin to collapse one after the other, affecting the bay under study and an adjacent one. The shores remaining at the end of the sequence shown in Fig. 12 experienced loads below their ultimate strength. In Fig. 12 the shores under slab 1 shown in red failed due to excessive loading in the following time step. As in the third scenario (Section 4.3), as a large number of shores failed between $t=0.64 \mathrm{~s}$ and $\mathrm{t}=0.74 \mathrm{~s}$, the shoring under slab 1 becomes more flexible, resulting in a larger deformation of slab 1 and an increase of the load carried by the remaining shores adjacent to those that have previously failed. This increased load can then reach the ultimate strength of $30.6 \mathrm{kN}$ in some of the remaining shores and cause their progressive collapse. Fig. 13 shows the deformations of the structure-shoring system after the extreme event at $\mathrm{t}=1.5 \mathrm{~s}$, in which the collapsed shores are not shown. 


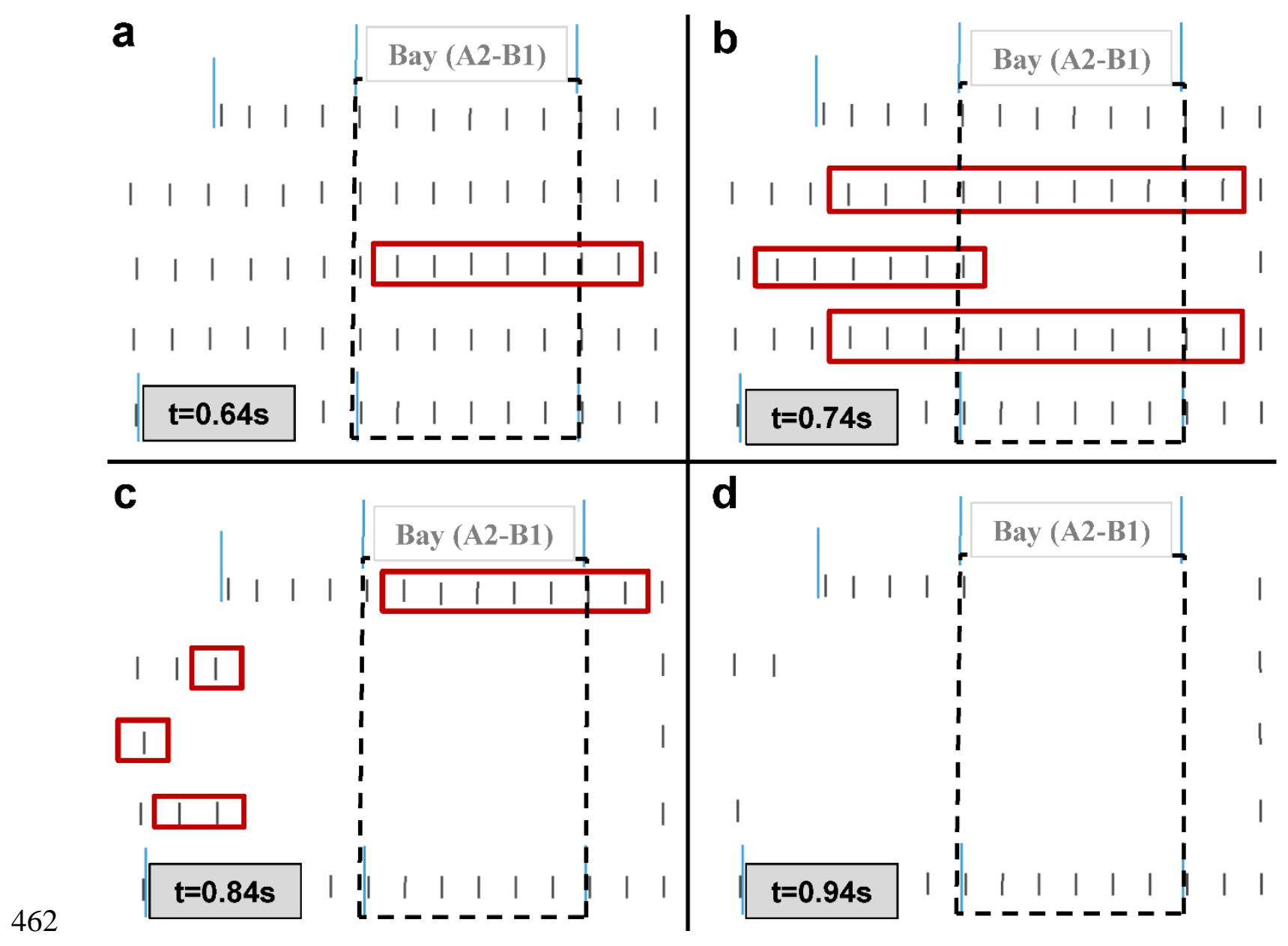

Fig. 12. Progressive collapse of the shoring system in the fourth scenario.

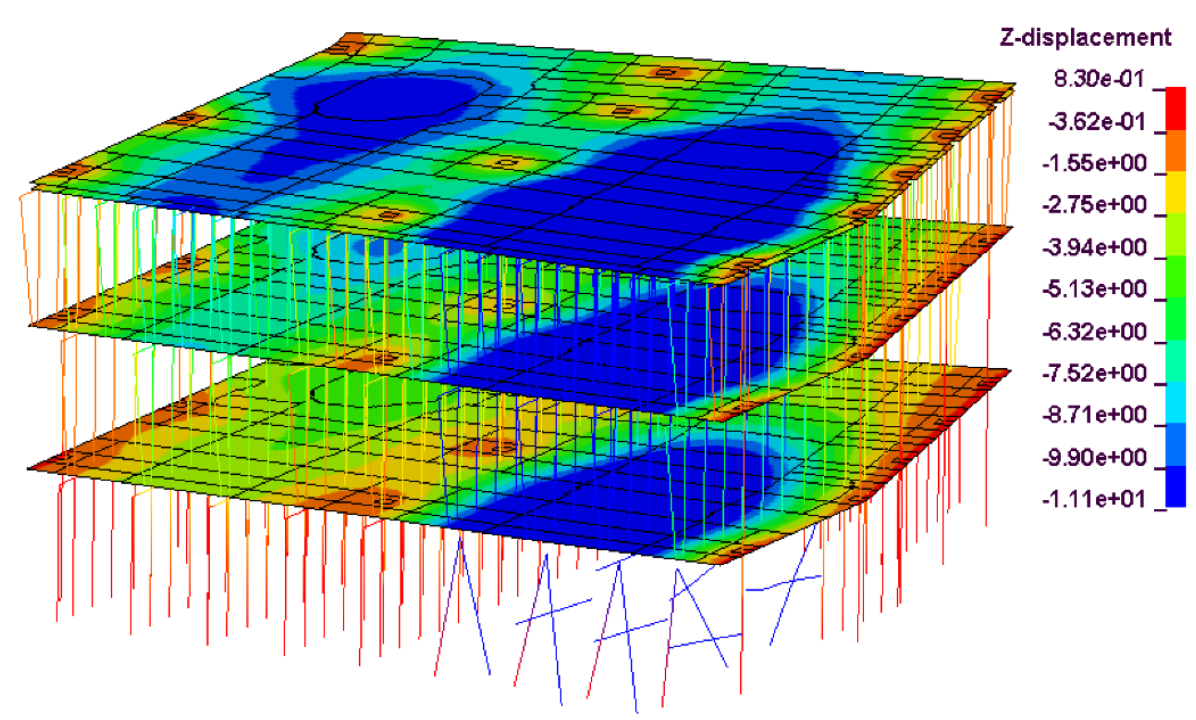

Fig. 13. Structure after the accidental event (units in mm). Collapsed shores are not shown.

466 Fig. 14 shows the main results obtained describing the structural behaviour. Fig. 14a shows

467 that the most heavily loaded shore under slab 1 reaches its ultimate strength at $\mathrm{t}=0.66 \mathrm{~s}$, and 
the load of the shore under slab 2 at the same time starts to reduce gradually (around 58\% reduction) during the progressive collapse of the shoring system. Similar to the preceding scenarios (Sections 4.1, 4.2 and 4.3), the reduced load on the shore under slab 2 is due to the increased deformation of slab 1 after the extreme event. The thickest lines in Fig. 14b show that the progressive collapse causes a sudden increment of the displacements in slabs 1 (about $47315.3 \mathrm{~mm}$ ) and 2 (about $14.0 \mathrm{~mm}$ ) at the position of the most heavily loaded shore under slab 1 474 (Fig. 2). The displacement is greater in slab 1 and thus confirming the load reduction (i.e. 475 decompression) on the shore under slab 2. In Fig. 14b it can also be seen how the extreme event in the bay under study has no effect on the adjacent bay (AB) A3-B2.

The loads per unit surface $\left(\mathrm{kN} / \mathrm{m}^{2}\right)$ carried by the shores (S) and slabs (Q) on each floor are given in Fig. 14c showing that the structural behaviour given by $S$ and Q changes significantly after the start of the progressive collapse. Due to the failure of some shores and the increased deformability of the shoring system under slab 1, the slab carries a higher load whereas the load on the shores is reduced. The greater deformability of slab 1 in turn increases the deformability of the support of slab 2 (slab 1 and shores under slabs 1 and 2) resulting in a higher load carried by slab 2 and less load carried by the shores. Fig. 14d contains the loaddisplacement curve of slabs 1 and 2 for the displacement at the position of the most heavily loaded shore under slab 1 . The slopes of the curves change suddenly at the start of the collapse showing a significant reduction of slab stiffness (i.e. high degree of cracking and flexural 487 deformations in the slab). 
a

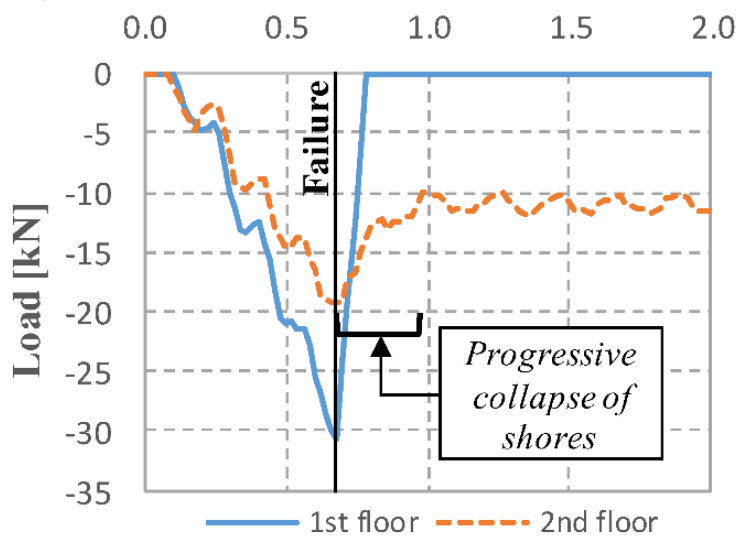

C

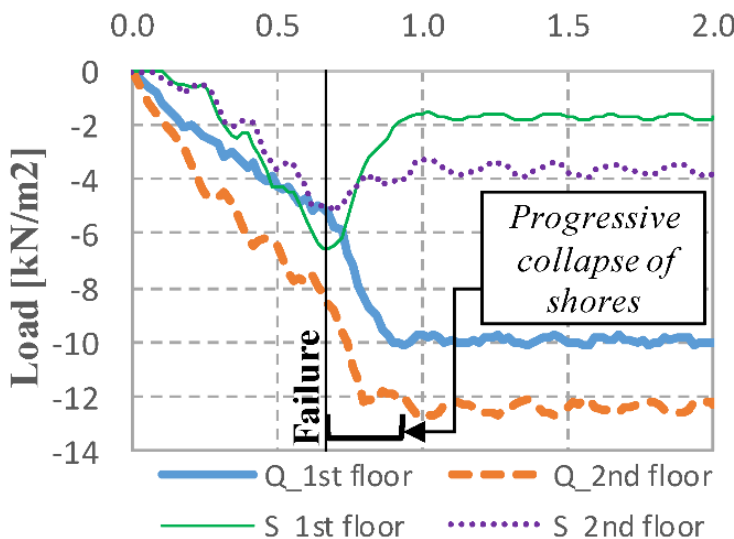

b

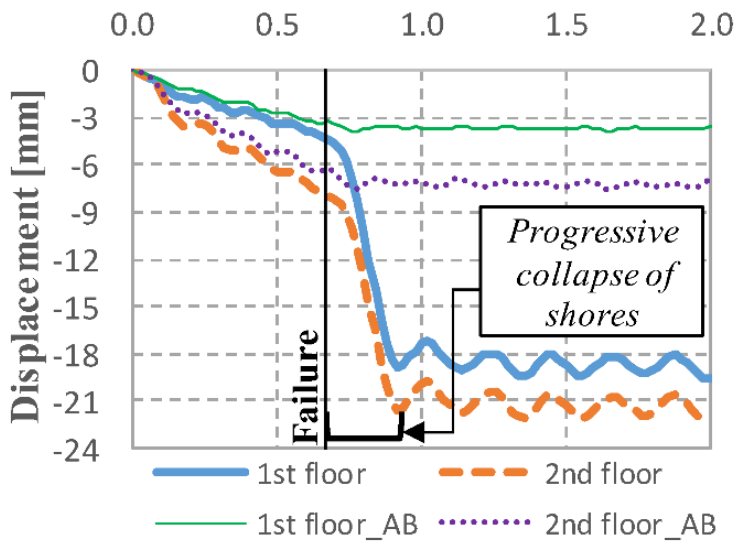

d

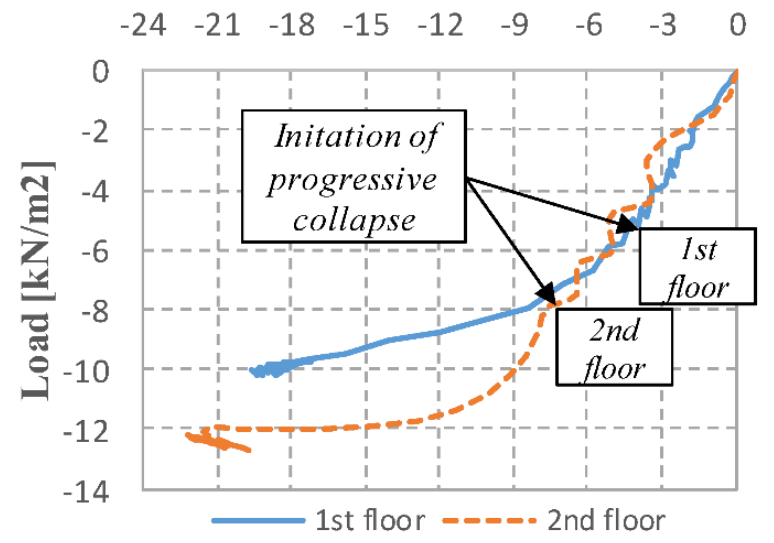

488

Fig. 14. Patterns of the behaviour of slabs and shoring in the fourth failure scenario: a) loads on shores under slab 1 and slab 2 at the position of the most heavily loaded shore under slab 1, b) displacement of slabs 1 and 2 at the position of the most heavily loaded shore under slab 1 in the bay under study and adjacent bay AB, c) loads on slabs (Q) and shores (S) of first and second floors, and d) load-displacement curve of slabs 1 and 2 at the position of the most heavily loaded shore under slab 1.

Fig. 15 gives the bending moments in both directions obtained from the FE model in the bay under study. Both the positive and negative moments of both slabs exceed the crack moments $(51.6 \mathrm{kN} \cdot \mathrm{m} / \mathrm{m}$ and $45.3 \mathrm{kN} \cdot \mathrm{m} / \mathrm{m}$ for the first and second slab, respectively) on a large part of the slab surface in the bay under study. Even under these high loads, the slabs comply with the ultimate strength flexure and punching requirements specified in Eurocode 2 [25] for the accidental load combination considered. 
501 ability to seek suitable alternative load paths, for which the load-sharing between slabs 1 and

5022 is again critical, as can be seen from their displacements and loads. Even though the slabs

503 carried significantly higher loads (Q) due to the event, and the deformability of the slabs was

504 higher than in previous scenarios, dynamic effects (i.e. loads and deflections) were not

505 generally observed in the analysis. Cracking of the slabs does increase after the extreme event,

506 thus seriously affecting its serviceability limit state performance and durability. Similar to

507 previous damaged scenario, in such situations it becomes necessary to assess the structural

508 safety of the building to determine possible repairs and whether it should be demolished. The

509 scale of consequence can be classified as "minor" or "low" according to IStructE [41] and EN

510 1991-1-7 [9] respectively.
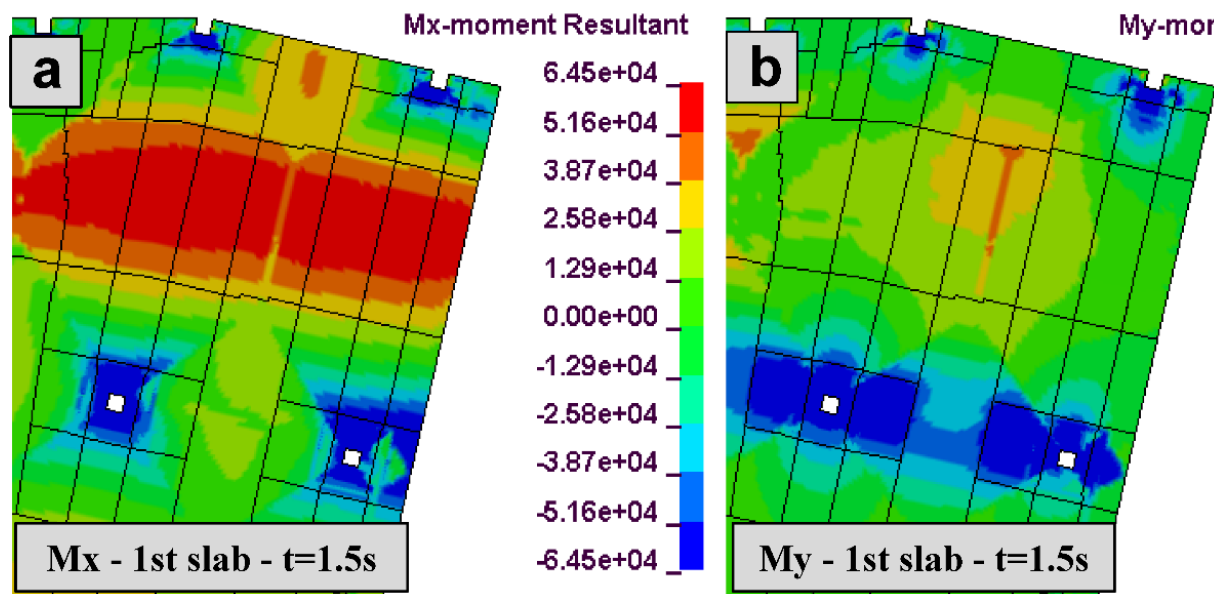

My-moment Resultant
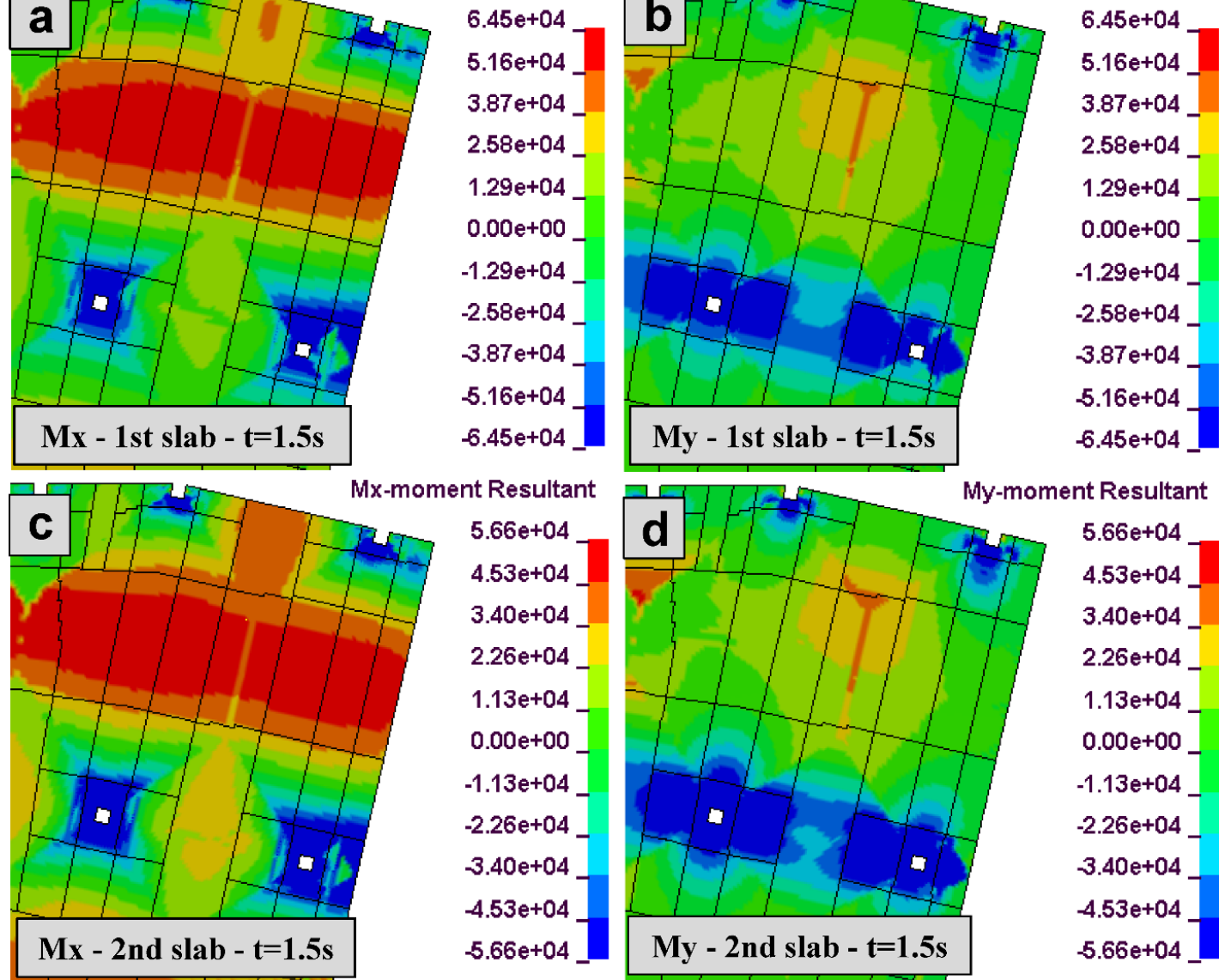

ent Resultant

Fig. 15. Bending moments of first ( $a$ and $b$ ) and second (c and d) slabs after the accidental event for the fourth 


\subsection{Dynamic amplification factor (DAF)}

The local damage scenarios described in Section 4 showed negligible dynamic

517 amplification effects (load and displacements) in the shoring elements or in the RC structure.

518 The fact that the axial forces in the shores and deflections in the structure after the sudden 519 removal of the shoring elements (see post-event results in Fig. 5, Fig. 6, Fig. 10 and Fig. 14) was the same as if the shoring elements had been removed gradually (i.e. dynamic amplification factor DAF = 1) was due to the relatively low deformation capacity of the structure-shore system after the accidental event and high redundancy. The introduction of local damage in the cases considered did not introduce significant velocities in the system (i.e. negligible kinetic energy) resulting in an almost quasi-static response with only some high frequency effects of minor importance. This response is significantly different to that observed in structures subjected to column or member loss (large kinetic energy and deflections) in which DAF can range from 1 up to 2 . The upper value of DAF corresponds to the theoretical linear response with no damping which is recommended for general actions during construction in EN 1991-1-6:2005 [31] for accidental actions such as local failure of temporary support. This work shows that for shoring systems using current practice and state-of-the art design methods DAF is equal to 1 for cases of the most loaded members removal. This finding is significant as using DAF = 1 allows to optimise the design for such situations whereas using $\mathrm{DAF}=2$ would result in rather conservative designs or unrealistic assessments of the consequences and risk of such events. However, as pointed out at the end of Section 6, the presented analysis performed as the first approach should be extended to other cases to confirm a suitable value for the DAF in order to be extensively applied in simplified approaches. 


\subsection{Tolerable risk considerations}

540 It has been shown that with correctly designed shoring an extreme event or local failure of

541 some of its components does not necessarily lead to the progressive collapse of the entire

542 structure. Although there is a higher likelihood of local failure during construction compared

543 to the serviceability stage (i.e. column loss), the consequences of these failures can be lower in

544 terms of cost and materials (generally the loss of human lives is limited). In the cases investigated with most serious consequences, it would be necessary to inspect the damage and assess the safety of the structure to decide whether it can be repaired or needs demolition. In terms of tolerable risk, the acceptable levels of risk given by guidelines such as IStructE [41] or Annex B in EN 1991-1-7 [9] will give relatively high values of acceptable probability of occurrence between $50 \%$ to $2 \%$ (corresponding to likely to rare likelihood respectively). A more refined systematic risk analysis would be needed if the structure had significant potential for instability during construction (i.e. Class 3 according to Harding and Carpenter [42]). heavily loaded shore are rather small, it seems unnecessary to include explicitly such events in the design phase. Nor is it necessary to consider the failure of multiple shores since this probability is even smaller. It is important to note that the integrity of the building is assured in such cases only assuming that both the structural design and the shoring system provided are sound. It is advisable to take into account: a) the construction process when designing

558 building structures, b) accurate and validated simplified calculation methods should be used to

559 correctly estimate the loads transmitted between slabs and shores during building work [1], and

560 c) it is also important to use the correct RC construction procedures to avoid stability issues

561 during temporary support situations. Even so, there is still room for the application of 562 mitigation techniques to reduce the risk, for example by using load limiters on shores $[2,10,43]$. 
563 These measures could contribute significantly towards reducing the high-risk of progressive

564 collapse observed in some cases during construction shown in Table 2.

565

566 6. Conclusions

567 This is the first study to focus on the structural response and damage of a building structure

568 under construction after the sudden failure of one or more shores. This is relevant in view of 569 the field evidence shown in Table 2 with many examples of hazards with intolerable high-risk with relatively medium likelihood and medium/high consequences (structural failures). The analysis was carried out on a real three-storey office building with RC flat-slabs designed according to Eurocode and shoring designed using a state-of-the-art and validated simplified calculation method providing accurate predictions of the axial loads in the shores. A dynamic explicit finite element analysis was performed to evaluate different local damage scenarios: 1) failure of the most heavily loaded shore, 2) failure of the joist on the most heavily loaded shore, 3) failure of the complete shore line on the most heavily loaded shore, and 4) the use of 577 incorrect shores.

578 In general, from all the situations analysed, the following can be concluded:

- When a shore fails the sharing of loads among the different slabs is critical to maintain the integrity of the structure. Due to the high stiffness of the structure-shoring system and high redundancy, the dynamic amplification obtained for the loads and deflections were negligible (i.e. DAF $=1$ ). This suggest that using DAF $=2$ as suggested in EN 1991-1-7 [9] for general cases of accidental actions during construction can be rather conservative and lead to unrealistic assessment of structural consequences and associated risk.

- The results showed that scenarios 1 and 2 with least structural effects did not cause the progressive collapse of neither the shoring nor the structure. In addition, slab cracking 
was negligible and the level of consequence could be classified as "minimal" or "very low" using standard risk assessment terminology.

- Scenarios 3 and 4 with higher structural effects resulted in the progressive collapse of the shoring, although the integrity of the structure was not affected. In such cases severe cracking was predicted to occur over most of the bay under study. In these situations, in order to avoid undesirable serviceability performance and durability issues during the operational stage, the structural safety should be evaluated in terms of damage, possible repairs or demolition.

- Since the failure scenarios studied had little effect on the integrity of the RC structure, it is not considered necessary to consider them explicitly when designing shoring systems on building RC structures. However, it has been shown in this work that it is very important to consider the construction process in the design of the structure and to Future works should study other specific failure scenarios of the shoring system that creates construction and in different floors.

611 
614 The authors would like to express their gratitude to the Spanish Ministry of Education,

615 Culture and Sport for funding received under: a) the FPU Program [FPU13/02466] and 616 complementary funding received for a stay at the University of Surrey (UK), and b) the 617 Mobility Program (Salvador de Madariaga 2017) of the Promotion of Talent and Employability 618 within the state's Research \& Innovation Program 2013-2016 [PRX17/00302]. The authors 619 would like to thank Dr. P. Olmati who developed the preliminary FE model of the structure at 620 the operational stage as part of a project sponsored by the EPSRC Impact Acceleration Account held by the University of Surrey (grant ref: EP/K503939) linked with a previous project funded by the EPSRC (grant ref: EP/K008153/1).

\section{References}

625

[1] Adam JM, Buitrago M, Moragues JJ, Calderón PA. Limitations of Grundy \& Kabaila's

626

627

628

629

630

631

632

633

634

635

636

637

638

639

640

641

642

643 simplified method and its repercussion on the safety and serviceability of successively shored building structures. J Perform Constr Facil 2017;31:1-10. doi:10.1061/(ASCE)CF.1943-5509.0001038.

[2] Buitrago M, Adam JM, Calderón PA, Moragues JJ. On the use of experimental testing in RC building structures under construction. In: Pellicer E, Adam JM, Yepes V, Singh A, Yazdani S, editors. Proc. Ninth Int. Struct. Eng. Constr. Conf., Valencia (Spain): ISEC press; 2017.

[3] Duan MZ, Chen WF. Improved simplified method for slab and shore load analysis during construction. Proj Rep CE-STR-95-21 1995.

[4] Fang DP, Geng CD, Zhu HY, Liu X La. Floor load distribution in reinforced concrete buildings during construction. ACI Struct J 2001;98:149-156.

[5] Calderón PA, Alvarado YA, Adam JM. A new simplified procedure to estimate loads on slabs and shoring during the construction of multistorey buildings. Eng Struct 2011;33:1565-1575. doi:10.1016/j.engstruct.2011.01.027.

[6] Buitrago M, Adam JM, Alvarado YA, Calderón PA, Gasch I. Maximum loads on shores during the construction of buildings. Proc Inst Civ Eng - Struct Build 2016;169:538545. doi:10.1680/jstbu.15.00089.

[7] Buitrago M, Adam JM, Calderón PA, Alvarado YA, Moragues JJ. Estimating loads on shores during the construction of RC building structures. Struct Concr 2016;17:502512. doi:10.1002/suco.201500130.

646 [8] BS 5975. Code of practice for temporary works procedures and the permissible stress 647 design of falsework. 2011. 
[9] EN 1991-1-7. Eurocode 1: Actions on structures - Part 1-7: General actions - Accidental actions. 2006.

[10] Buitrago M, Moragues JJ, Calderón PA, Adam JM. Structural failures in cast-in-place RC building structures under construction. In: Makhlouf ASH, Aliofkhazraei M, editors. Handb. Mater. Fail. Anal. with Case Stud. from Constr. Ind. Vol. 6. 1st ed, ButterworthHeinemann, Elsevier; 2018, p. 560. doi:10.1016/ B978-0-08-101928-3.00008-2.

[11] Hadipriono FC, Wang H-K. Causes of falsework collapses during construction. Struct Saf 1987;4:179-195. doi:10.1016/0167-4730(87)90012-9.

[12] Carper KL. Structural Failures During Construction. J Perform Constr Facil 1987;1:132-144. doi:10.1061/(ASCE)0887-3828(1987)1:3(132).

[13] Kaminetzky D. Structural Failures and How to Prevent Them. Civ Eng 1976;46:60-73.

[14] Eldukair ZA, Ayyub BM. Analysis of Recent U.S. Structural and Construction Failures. J Perform Constr Facil 1991;5:57-73. doi:10.1061/(ASCE)0887-3828(1991)5:1(57).

[15] Soane A. Learning from experience to avoid collapse. Proceeding Inst Civ Eng Forensic Eng 2016;169:127-32. doi:10.1680/jfoen.16.00004.

[16] Olmati P, Sagaseta J, Cormie D, Jones AEK. Simplified reliability analysis of punching in reinforced concrete flat slab buildings under accidental actions. Eng Struct 2017;130:83-98. doi:10.1016/j.engstruct.2016.09.061.

[17] Fascetti A, Kunnath SK, Nisticò N. Robustness evaluation of RC frame buildings to progressive collapse. Eng Struct 2015;86:242-249. doi:10.1016/j.engstruct.2015.01.008.

[18] Bao Y, Kunnath SK, El-Tawil S, Lew HS. Macromodel-Based Simulation of Progressive Collapse: RC Frame Structures. J Struct Eng 2008;134:1079-1091. doi:10.1061/(ASCE)0733-9445(2008)134:7(1079).

[19] El-Tawil S, Li H, Kunnath S. Computational Simulation of Gravity-Induced Progressive Collapse of Steel-Frame Buildings: Current Trends and Future Research Needs. J Struct Eng 2014;140:1-12. doi:10.1061/(ASCE)ST.1943-541X.0000897.

[20] Qian K, Li B. Performance of Three-Dimensional Reinforced Concrete Beam-Column Substructures under Loss of a Corner Column Scenario. J Struct Eng 2013;139:584594. doi:10.1061/(ASCE)ST.1943-541X.0000630.

[21] Yi W-J, Kunnath SK, Zhang F-Z, Xiao Y. Large-scale experimental evaluation of building system response to sudden column removal. Struct. Congr. 2011, vol. 1, ASCE 2014; 2011, p. 2353-2357.

[22] Pham AT, Tan KH, Yu J. Numerical investigations on static and dynamic responses of reinforced concrete sub-assemblages under progressive collapse. Eng Struct 2016. doi:10.1016/j.engstruct.2016.07.042.

[23] Ren P, Li Y, Lu X, Guan H, Zhou Y. Experimental investigation of progressive collapse resistance of one-way reinforced concrete beam-slab substructures under a middlecolumn-removal scenario. Eng Struct 2016;118:28-40. doi:10.1016/j.engstruct.2016.03.051.

[24] Brunesi E, Nascimbene R, Parisi F, Augenti N. Progressive collapse fragility of reinforced concrete framed structures through incremental dynamic analysis. Eng Struct 2015;104:65-79. doi:10.1016/j.engstruct.2015.09.024. 
[25] EN 1992-1-1. Eurocode 2: Design of concrete structures - Part 1-1: General rules and rules for buildings. 2004 .

[26] DoD. Department of Defense. Design of buildings to resist progressive collapse (UFC 4-023-03). 2009.

[27] GSA. General Services Administration. Progressive collapse analysis and design guidelines for new federal office buildings and major organization projects. 2000.

[28] CS: Concrete Society. Guide to the design and construction of reinforced concrete flat slabs. Technical report no 64; 2007.

[29] ACI 318-14. Building Code Requirements for Structural Concrete. 2014.

[30] AS 3610. Australian standard formwork for concrete. 2010.

[31] EN 1991-1-6. Eurocode 1: Actions on structures - Part 1-6: General actions - Actions during execution. 2005.

[32] EN 1990. Eurocode: Basis of structural design. 2002.

[33] Buitrago M, Adam JM, Alvarado YA, Moragues JJ, Gasch I, Calderón PA. Designing construction processes in buildings by heuristic optimization. Eng Struct 2016;111:110. doi:10.1016/j.engstruct.2015.12.009.

[34] Alvarado YA, Calderón PA, Gasch I, Adam JM. A numerical study into the evolution of loads on shores and slabs during construction of multistorey buildings. Comparison of partial striking with other techniques. Eng Struct 2010;32:3093-3102. doi:10.1016/j.engstruct.2010.05.028.

[35] Alsina Formwork Solutions 2017. http://www.alsina.com/.

[36] LSTC. LS-DYNA theory manual. 2012.

[37] Kernes RG, Edwards JR, Dersch MS, Lange DA, Barkan CPL. Investigation of the Dynamic Frictional Properties of a Concrete Crosstie Rail Seat and Pad and its Effect on Rail Seat Deterioration (RSD). Transp. Res. Board 91st Annu. Meet., Illinois: Railtec; 2011, p. 14.

[38] Gorst JS, Williamson SJ, Pallett PF, Clark LA. Research Report 071: Friction in temporary works. Birmingham: 2003.

[39] Dat PX, Tan KH. Experimental Response of Beam-Slab Substructures Subject to Penultimate-External Column Removal. J Struct Eng 2015;141:1-12. doi:10.1061/(ASCE)ST.1943-541X.0001123.

[40] Sagaseta J, Ulaeto N, Russell J. Structural robustness of concrete flat slab structures. ACI Struct J 2017;315:273-298.

[41] Institution of Structural Engineers (IStructE). Manual for the systematic risk assessment of high-risk structures against disproportionate collapse. London: IStructE and supported by the Department for Communities and Local Goverment; 2013.

[42] Harding G, Carpenter J. Disproportionate collapse of "class 3" buildings: The use of risk assessment. Struct Eng 2009;87:29-34.

[43] Buitrago M, Alvarado YA, Adam JM, Calderón PC, Gasch I, Moragues JJ. Improving construction processes of concrete building structures using load limiters on shores. Eng Struct 2015;100:104-115. doi:10.1016/j.engstruct.2015.06.007. 